\title{
Measured short-term ground surface response to EPBM tunnelling in London Clay
}

\section{S. P. WAN* J. R. STANDING $\dagger$, D. M. POTTS $\uparrow$ and J. B. BURLAND $\dagger$}

\begin{abstract}
Earth-pressure-balance machines (EPBMs) were used for the construction of Crossrail tunnels in London, providing opportunities for field investigation of consequent ground response. Analysed results from an instrumented research site in Hyde Park with extensive surface and subsurface monitoring arrays are presented and discussed. The Crossrail tunnels at the site are $34.5 \mathrm{~m}$ below ground, deeper than those in most case histories of tunnelling in stiff clay in the UK. This paper characterises the tunnelling-induced ground response, both 'greenfield' and in the proximity of the existing Central Line tunnels, dealing with measurements at the ground surface. A companion paper covers the subsurface ground response. Vertical and horizontal ground surface displacements were obtained from manual precise levelling and micrometer stick measurements. Several key findings will benefit future tunnelling projects involving EPBMs. Volume loss values measured at the instrumented site were low, being less than $0 \cdot 8 \%$ and $1.4 \%$ for the first and second tunnel drives respectively, higher values being associated with ground softening from the first tunnel construction. Smaller volume losses were recorded in the vicinity of the existing Central Line tunnels, compared with the greenfield location, suggesting that their presence inhibited the development of ground movements. Asymmetric settlement troughs developed due to either the nearby pre-existing tunnels or the construction of the first tunnel. Marginally smaller values of trough width parameter, $K_{y}$, were determined for these deeper tunnels compared with previous greenfield ground case histories. Resultant vectors of ground surface displacement were directed to well-defined point-sinks above the tunnel axis level.
\end{abstract}

KEYWORDS: field instrumentation; ground movements; monitoring; settlement; tunnels \& tunnelling

\section{BACKGROUND}

In major cities like London, constructing new tunnels inevitably influences nearby existing structures above and within the ground. Much has been learnt about the complex interactions between the ground and existing underground structures from new tunnel construction reported through case studies. With advances in tunnelling technologies and practices and construction materials, engineers and researchers continuously endeavour to update and improve their understanding of ground and structural responses to tunnel construction. Recently a comprehensive research project has been run by Imperial College London to investigate the effect of tunnelling by modern earth-pressure-balance tunnel-boring machines (EPBMs) on existing tunnels (Standing et al., 2015). Field measurements at an instrumented site in Hyde Park formed an integral part of the overall research project.

Short-term tunnelling-induced ground surface displacements are still frequently predicted using empirical approaches (Attewell, 1978). Vertical displacements are estimated using a Gaussian formulation where there are two unknowns: volume $\operatorname{loss}\left(V_{\mathrm{L}}\right)$ and the trough width parameter $(K)$. Of these, volume loss is the more difficult to predict, it depends on various factors such as method of tunnelling, ground and groundwater conditions, and the time period before support to the excavated ground is provided. In this paper volume loss is taken to be the

Manuscript received 12 April 2016; revised manuscript accepted 23 September 2016. Published online ahead of print 16 November 2016.

Discussion on this paper closes on 1 October 2017, for further details see p. ii.

Published with permission by the ICE under the CC-BY 4.0 license. (http://creativecommons.org/licenses/by/4.0/)

* Geotechnical Consulting Group LLP, London, UK.

$\dagger$ Imperial College London, London, UK. volume of the surface settlement trough divided by the nominal volume of the excavated tunnel. The $K$ value is the ratio of the surface distance between the tunnel centre-line position and the point of inflection, $i_{y}$ (sometimes referred to as the trough width factor), to the depth to the tunnel axis, $z_{0}$ (i.e. $K=i_{y} / z_{0}$ ). Horizontal displacements at the surface are often estimated by assuming that resultant vectors of displacements are directed towards a single 'point-sink', usually taken to be the tunnel axis. Thus, after predicting the vertical displacement, the horizontal displacement can be readily calculated: it is zero directly above the tunnel and reaches a maximum at the offset distances $i_{y}$ Horizontal strains $\left(\varepsilon_{\mathrm{h} y}\right)$ can be obtained by differentiating the horizontal displacements. There are two distinct zones with compressive strains between the points of inflection either side of the tunnel centre line (where $\varepsilon_{\mathrm{h} y}=0$ ), beyond which strains are tensile. In this paper the measurement data are discussed in the context of these empirical prediction approaches.

After describing the instrumented field site, the monitoring results are presented and discussed with the aim of characterising the ground surface response induced by tunnelling with EPBMs, both in 'greenfield' conditions and in the proximity of existing tunnels. The greenfield ground response is compared with those from other well-instrumented greenfield sites, for example, Nyren (1998) and Withers (2001) for the Jubilee Line Extension (JLE) and Selemetas (2005) for the Channel Tunnel Rail Link (CTRL). In a companion paper, the nature and mechanism of subsurface ground displacements are studied and correlated with measured EPBM operation variables.

\section{CROSSRAIL TUNNELLING AND INSTRUMENTED SITE}

The Crossrail project involves construction of $21 \mathrm{~km}$ of twin-bore tunnels and nine underground stations beneath 

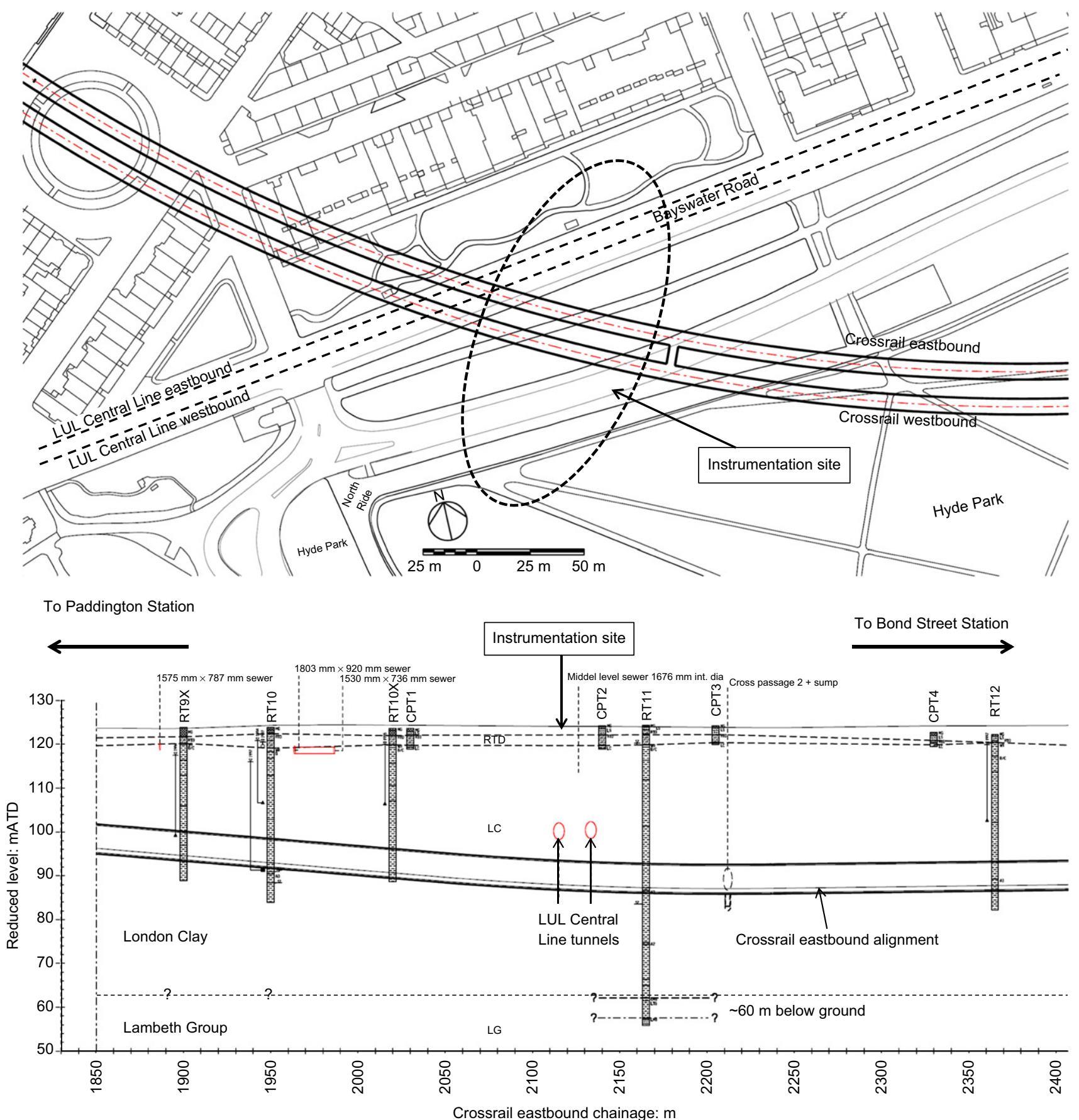

Fig. 1. Location plan of instrumentation site and longitudinal section of Crossrail eastbound tunnel

central London. The instrumented site in Hyde Park lies on the tunnel alignment which runs from the Royal Oak portal west of Paddington Station to Farringdon Station. The first tunnel-boring machine (TBM1) was used to construct the westbound tunnel and passed beneath the Hyde Park instrumented site in late November 2012, whereas the second, TBM2, used for the eastbound tunnel passed beneath the site in early February 2013. Average driving speeds were about $110 \mathrm{~m}$ per week.

On the northern boundary of Hyde Park, just east of Lancaster Gate, the TBMs passed beneath the existing London Underground (LUL) $3.8 \mathrm{~m}$ dia. Central Line running tunnels below Bayswater Road at a skew angle of about $40^{\circ}$ (as shown in Fig. 1 along with a longitudinal section of the eastbound Crossrail tunnel). At the crossing, the axes of the Central Line and Crossrail tunnels are about $24 \mathrm{~m}$ and $34.5 \mathrm{~m}$ below ground level (mbgl), respectively: the clearance between the respective tunnel inverts and crowns ranges from $4.3 \mathrm{~m}$ to $5.0 \mathrm{~m}$. Both pairs of tunnels are within the London Clay Formation (LCF). Extensive field instrumentation was installed just east of Victoria Gate, within Hyde Park and on Bayswater Road, to investigate the ground response close to the existing tunnels and also in the greenfield condition.

\section{SITE GEOLOGY}

The stratigraphy at Hyde Park is typical of that within the London Basin with deposits from the LCF, Lambeth Group and Thanet Sand resting on Chalk bedrock. As part of the Hyde Park instrumentation installations, a 68-m deep borehole (denoted HP6 - Fig. 4(a)) was sunk by rotary core drilling through the whole thickness of LCF and part of the Lambeth Group. Continuous triple tube core barrel samples 


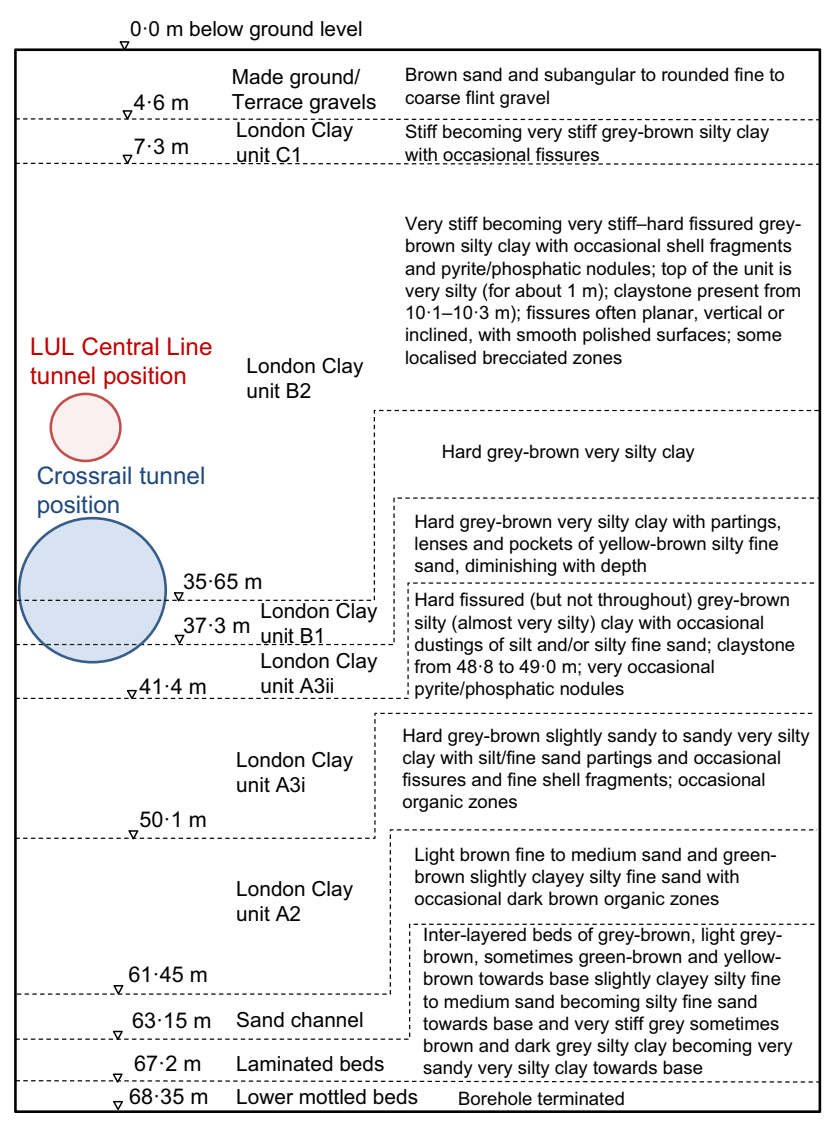

Fig. 2. Soil description and ground stratification at instrumentation site determined from borehole HP6 were transported to Imperial College for detailed logging. The lithological units of the LCF, as characterised by King (1981), were identified by visual inspection and moisture content measurements (Standing \& Burland, 2006).

Figure 2 shows the soil descriptions and stratification of the ground determined from borehole HP6, together with the relative depth of the Central Line and Crossrail tunnels. At the instrumented site, the Chalk bedrock is inferred to be about $80 \mathrm{mbgl}$ from deep boreholes at Paddington and Hyde Park, overlain by a thin layer of Thanet Sand (about $3.5 \mathrm{~m}$ thick) and about a $15 \mathrm{~m}$ thickness of Lambeth Group deposits. A 1.7-m deep sand-infilled channel was encountered below the London Clay, which had eroded the upper units of the Lambeth Group. The base of the LCF, which has an overall thickness of about $57 \mathrm{~m}$, is at $61.5 \mathrm{mbgl}$. There is a 3-m thick layer of Terrace Gravel above the LCF, with a thin layer of made ground at the surface. Most of the $7 \cdot 1 \mathrm{~m}$ dia. Crossrail tunnel excavation is within the lower level of the LCF unit B (B1 and B2), while its invert is within the more permeable A3ii unit.

During borehole drilling at the site, three horizons with large concentrations of claystones were encountered within the LCF, the greatest being from 29.5 to $30 \mathrm{mbgl}$. The implication of these on the ground permeability and the groundwater regime has been discussed by Wan \& Standing (2014b). It is possible that these extensive claystone horizons might also affect the response of other instruments such as inclinometers and extensometers.

\section{INSTRUMENTATION LAYOUT AND MONITORING}

The instrumentation layout, shown in Fig. 3, was designed to monitor the ground responses induced by the passage of

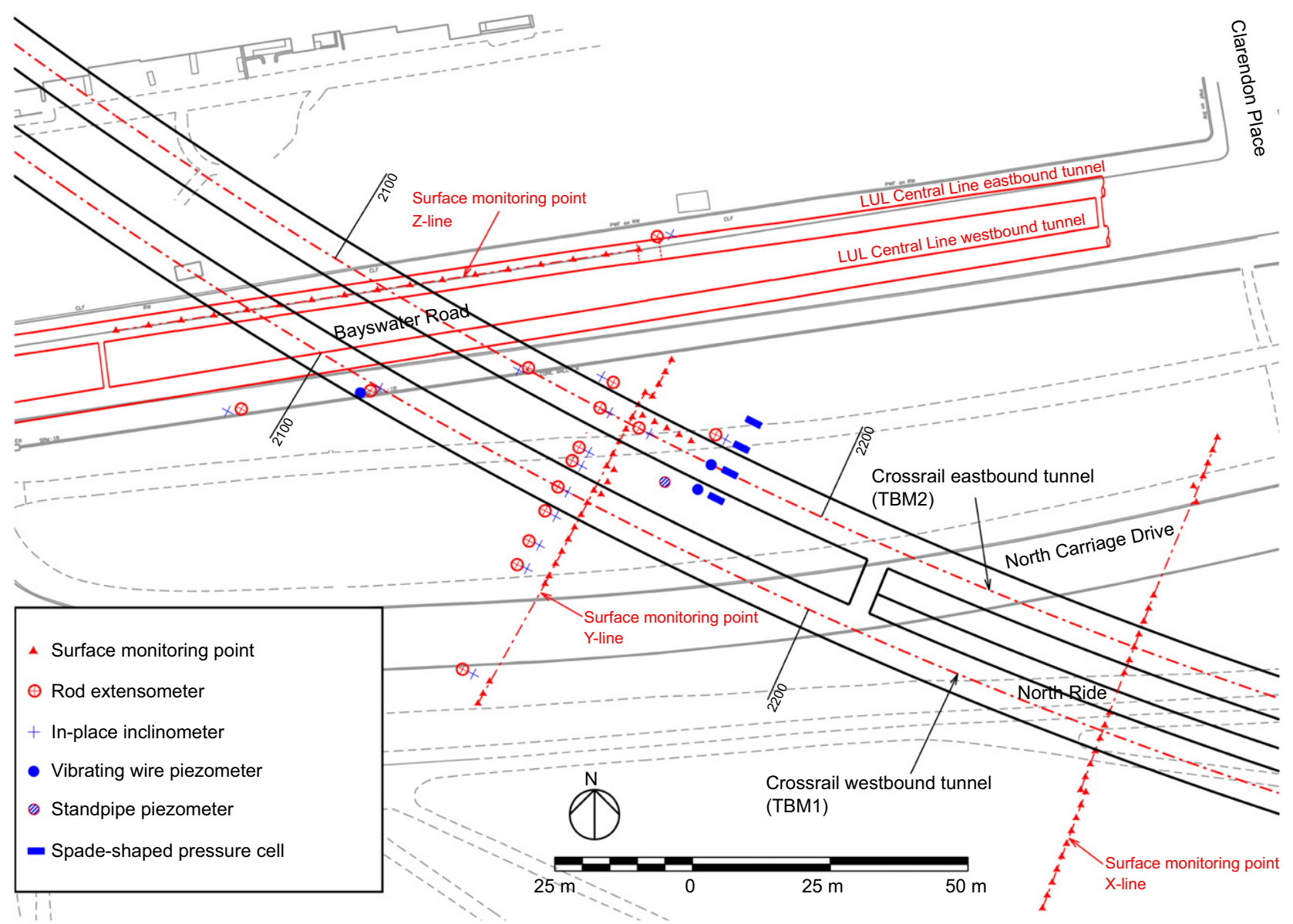

Fig. 3. Instrumentation layout plan 
both TBMs. There are 38 boreholes in total, each accommodating one or more instruments.

Ground surface measurements were made predominantly using surface monitoring points (SMPs) of a design similar to that described by Nyren (1998). Within the boundary of Hyde Park there are two lines of SMPs, the X-line and Y-line, both being transverse to the Crossrail alignments, on which vertical and horizontal displacements were measured by precise levelling, total stations and a micrometer stick. These SMPs incorporate BRE-type sockets (BRE, 1993) into which a removable survey plug can be screwed with good positional repeatability for manual surveying (Standing et al., 2001). A greenfield response is expected across the entire X-line. Along the Y-line, the SMPs are positioned to measure, in the southwest part, the greenfield ground response and, in the northeast part, the ground response under the potential influence of the Central Line tunnels (for the case of the first, westbound, tunnel drive). Different responses would be expected for these two parts. Another line of SMPs (Z-line) comprised typical survey nails installed in the kerbstones on the northern pavement of Bayswater Road, which runs above the Central Line eastbound running tunnel. Detailed plans indicating the locations and nomenclature of the SMPs and borehole instruments are shown in Figs 4(a) and 4(b). It is worth noting that both the $\mathrm{X}$ - and Y-lines cross the North Carriage Drive and so there are gaps in the lines at these points.

Details of the instruments and their installation are described by Wan \& Standing (2014a). The performance and uncertainties and errors associated with the measurement techniques, including precise levelling and micrometer stick measurement, were assessed and reviewed during the pre-construction period (Fearnhead et al., 2014; Wan, 2014). Although measurements were taken for the duration of each TBM passage using robotic total stations, set up to sight to optical prisms screwed into sockets installed into the heads of the SMPs, these are not presented in this paper. Total station measurements have the benefit of providing displacements in three orthogonal coordinate directions. However, better accuracy was achieved from the measurements made with the precise levelling and micrometer stick, and so only these are presented. Displacements in the third direction, longitudinal to the TBM drives, were small and results from the total station monitoring could not be interpreted reliably. In addition to the micrometer stick measurements, optical fibres were installed independently within a narrow trench by a research team from ETH Zurich to measure horizontal strains. The set-up and measurements are described by Hauswirth et al. (2014) and the results are compared with the micrometer stick measurements later in this paper.

\section{TUNNEL-BORING MACHINES}

The Herrenknecht EPBMs that passed beneath the site had a total length of $150 \mathrm{~m}$, with a rotating full-face cutterhead of $7.1 \mathrm{~m}$ dia. and a leading shield body $11 \mathrm{~m}$ long. The two EPBM cutter-heads have identical dimensions and arrangements of cutting tools on the cutting wheel. Each cutter-head has eight radial arms which are equipped with optional cutting configurations of clay spades $(210 \mathrm{~mm}$ projection from the hard face) or ripper tools $(140 \mathrm{~mm}$ projection). The cutter-head of TBM1 was configured using

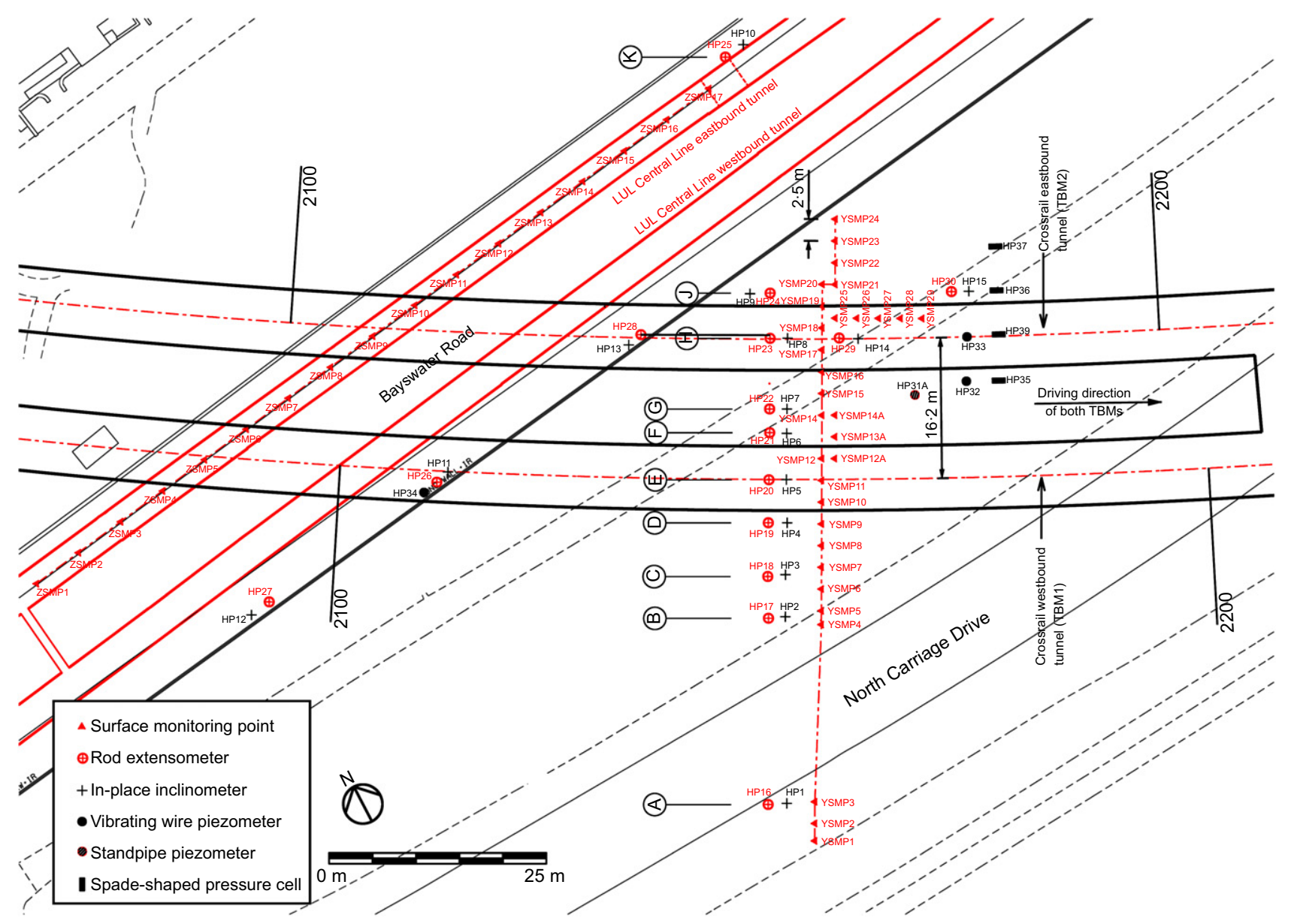

(a)

Fig. 4. Location plan of instruments: (a) Z-line and Y-line SMPs and borehole instruments; (b) X-line SMPs (continued on next page) 


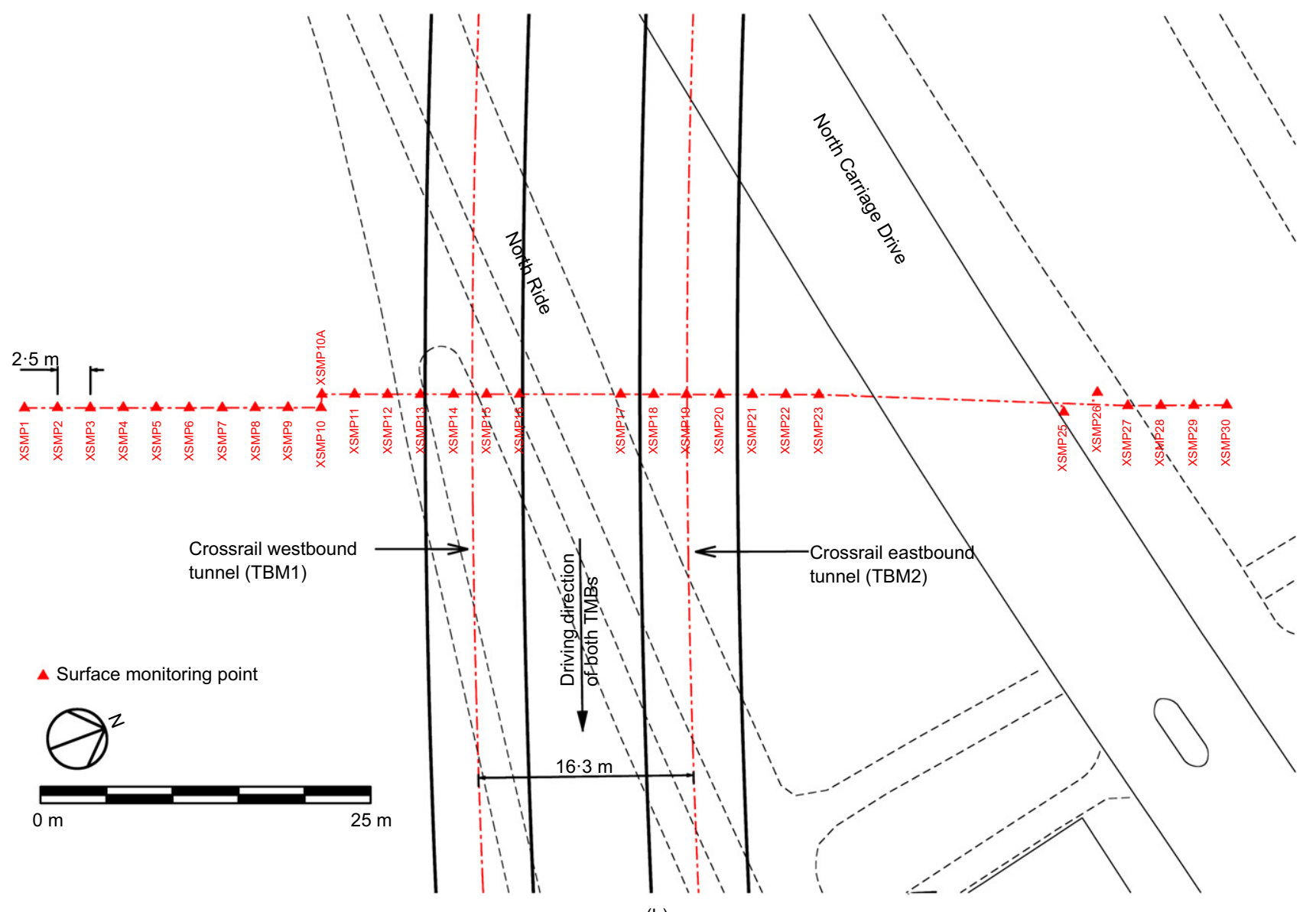

(b)

Fig. 4. Continued

the traditional clay spade while that of TBM2 had a standard ripper system. At the ends of four of the radial arms are $432 \mathrm{~mm}$ dia. cutter discs which define the bore diameter of $7100 \mathrm{~mm}$ (Fig. 5). Although the reason for the different cutting configurations used for the two TBMs is unknown to the authors, it is thought that the cutting option (ripper or clay spade) should not have a significant effect on the achieved volume loss per metre advance of the cutter-head. Soil passed into the plenum chamber behind the cutter-head through apertures, providing a nominal opening ratio of 55\% at the face. The shield body was tapered in shape with the outer diameter varying from $7.08 \mathrm{~m}$ at the front to $7.05 \mathrm{~m}$ at the rear. An Archimedes screw conveyor, connected to the sealed pressurised plenum chamber, was used to remove spoil. The face pressure was controlled by the rate of spoil removal, with the aim of minimising changes in earth pressure at the front of the cutter-head. Precast concrete lining rings, formed of seven segments and a key-piece, were erected within the shield body and the shield was advanced by a series of hydraulic jacks pushing against the newly erected lining. The inner and outer diameters of the rings were $6.2 \mathrm{~m}$ and $6.8 \mathrm{~m}$, respectively, and had a nominal length of $1600 \mathrm{~mm}$ (there was a $60 \mathrm{~mm}$ taper so $1570 \mathrm{~mm}$ and $1630 \mathrm{~mm}$ on the narrow and wide sides, respectively). The annular void between the erected tunnel lining extrados and the excavated ground was grouted by means of injection ports located within the tail skin of the shield. The tail grout was pumped continuously as the shield advanced. The grout used was a two-part mix combining a retarded grout (with proportions of water: cement: PFA: bentonite of 1.00: 0.25: 0.10: 0.05 and a small amount of retarder) with an accelerator prior to exiting the injection ports.
Eight pressure sensors were distributed behind the cutterhead to measure the face pressures and other pressure sensors were also present in the pressurised chamber and the screw conveyor. The tunnelling contractor used a real-time system to monitor closely a number of operation variables, including the machine position, advance speed, face pressure, tail grout pressure, tail grout volume and weight of excavated material on the conveyor belt. These provide useful information for construction control as well as for assessing their effects on the ground response to the construction.

\section{SURFACE MONITORING RESULTS}

The monitoring data have been divided into five distinct periods.

(a) Period 1 - pre-construction (12 October 2011 to 19 November 2012).

(b) Period 2 - construction of the westbound tunnel by TMB1 (19 November 2012 to 30 November 2012).

(c) Period 3 - interim phase before TMB2 arrived (30 November 2012 to 3 February 2013).

(d) Period 4 - construction of the eastbound tunnel by TMB2 (3 February 2013 to 12 February 2013).

(e) Period 5 - long-term monitoring (12 February 2013 onwards).

Data from the base-line monitoring during period 1 are discussed by Fearnhead et al. (2014), whereas this paper concentrates on the short-term responses observed during periods 2 and 4. 


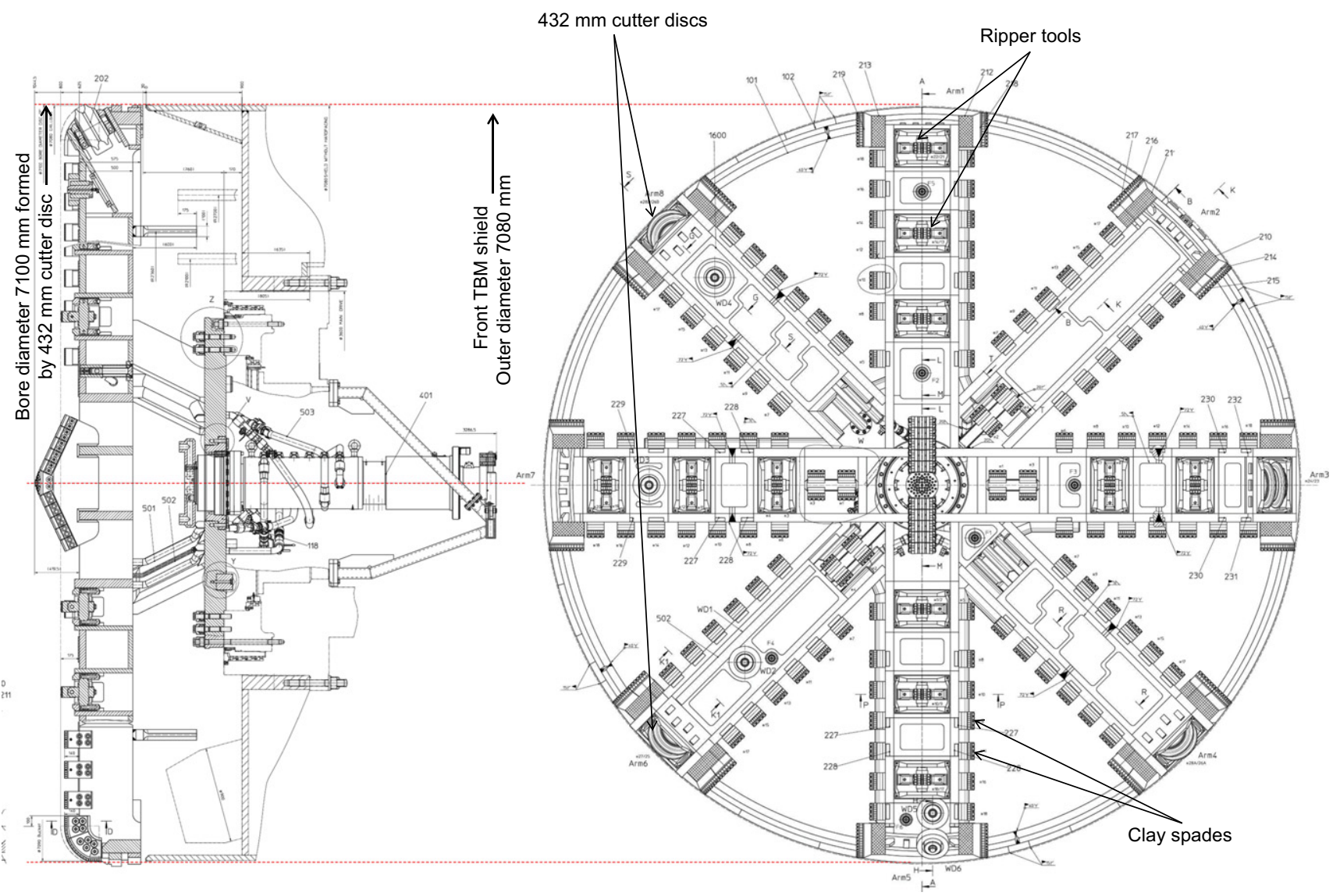

Fig. 5. Cutting configuration of cutter-head of TBM1 and TBM2 (courtesy of Crossrail and Herrenknecht)

The sign conventions for presentation of the monitoring results are as follows.

(a) Positive $(+) x$ means the longitudinal distance ahead of the TBM cutter-head.

(b) $x_{\mathrm{f}}$ is the longitudinal horizontal distance between the cutter-head and the monitoring point/line in question. $(-) x_{\mathrm{f}}$ means the cutter-head is in front of and approaching the monitoring point/line while $(+) x_{\mathrm{f}}$ means the cutter-head is progressing beyond the monitoring point/line.

(c) Positive $(+) y$ means the transverse horizontal distance from the tunnel axis to the left-hand side when looking in the direction of tunnel advancement.

(d) Negative $(-) z$ means the downwards vertical distance from the ground surface.

(e) $u, v$ and $w$ are the displacements in the directions and senses of $x, y$ and $z$, respectively.

$(f)$ The depth of the tunnel axis below ground surface is denoted by $z_{0}$ (a positive value).

The TBMs passed beneath the site at the Z-line SMPs first, followed by the Y-line SMPs, and subsequently the X-line SMPs. Figs 6(a) and 6(b) show the cutter-head advance timelines, chainage locations of the instruments, and the times of precise levelling surveys during the passages of TBM1 and TBM2, respectively.

It can be seen from Fig. 6(a) that the first tunnel construction was suspended a number of times for up to $30 \mathrm{~h}$ at a time. These suspensions resulted from multiple delays in removing excavated spoil from the tunnelling shield because of failures of the conveyor and hopper muck-away system when the first TBM was passing beneath the Paddington and Hyde Park area. The face pressure was thought to be fully maintained during the suspensions. One such suspension occurred when the TBM1 cutter-head was about $5 \mathrm{~m}$ in front of the Y-line SMPs $\left(x_{\mathrm{f}}=-5 \mathrm{~m}\right)$. A total of five precise levelling survey sets were performed during the $30 \mathrm{~h}$ of suspension. Vertical displacements of less than $0.2 \mathrm{~mm}$ were measured, which is within the precise levelling measurement accuracy. This suggests that the construction break of $30 \mathrm{~h}$ did not have a significant effect on the measured ground surface displacements.

\section{VERTICAL DISPLACEMENTS}

The vertical displacements for periods 2 and 4 presented in this paper refer to incremental displacements with reference to when the TBM cutter-head distances were about $100 \mathrm{~m}$ in front of the instrument lines (i.e. $x_{\mathrm{f}} \approx-100 \mathrm{~m}$ ).

\section{Vertical displacements on Z-line (periods 2 and 4)}

The Z-line SMPs, being located above and along the existing eastbound Central Line alignment, allowed the development of vertical displacements on a line at a skew angle to the TBM advance direction to be measured. The progressive settlement troughs developed along the Z-line as TBM1 and TBM2 passed the line are shown in Figs 7(a) and 7(b), respectively (note that the perpendicular horizontal distance of the monitoring point from the TBM axis is plotted, rather than the distance along the Z-line). Across the settlement trough obtained from any one survey, the longitudinal distance between the cutter-head and each ZSMP is different because of the skew angle between the Z-line and the TBM driving direction. For this reason, the shortterm transverse settlement trough for a particular cutter-head location cannot be readily obtained without some adjustment 


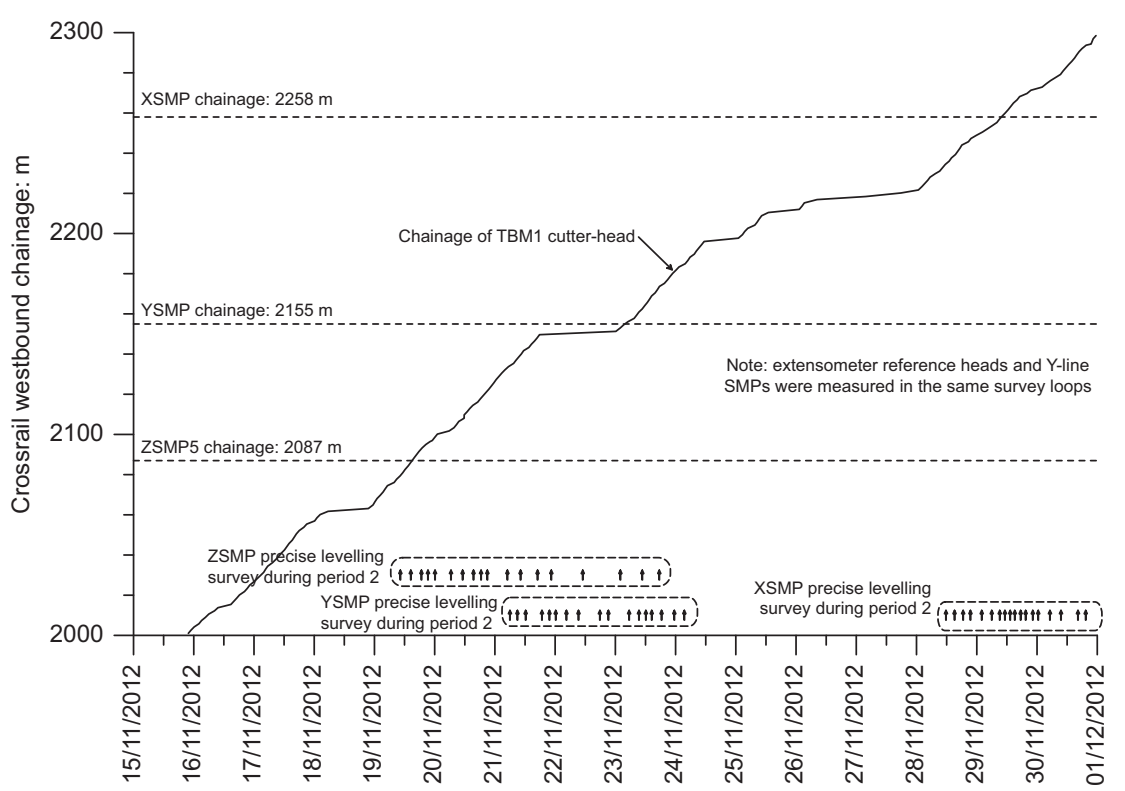

(a)

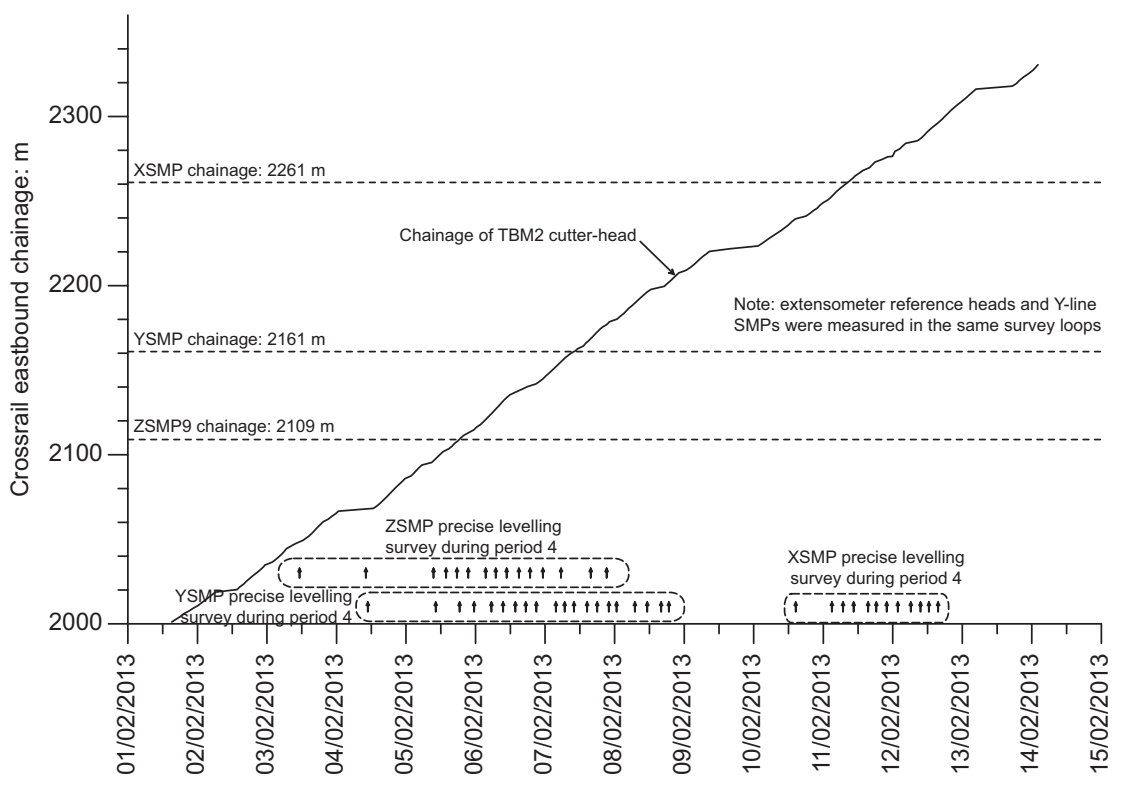

(b)

Fig. 6. Time of precise levelling survey loops: (a) during passage of TBM1 (westbound tunnel-period 2); (b) during passage of TBM2 (eastbound tunnel - period 4)

to the measurement results. Equally, the volume loss and trough width parameter for the Z-line cannot be determined directly from the settlement troughs shown in Figs 7(a) and 7(b). Nevertheless, a general pattern of the developing maximum settlement location shifting as the cutter-head position varies is evident, with the final maximum settlement occurring and remaining at or near the TBM centre-line location $(y=0)$. The maximum settlements recorded were $5.1 \mathrm{~mm}$ and $9 \cdot 5 \mathrm{~mm}$ for the west- and eastbound tunnels, respectively. This general pattern is similar to that observed in the existing Piccadilly Line tunnel when the TBM used to construct the Heathrow Express tunnels passed beneath it, also at a skew angle (Cooper et al., 2002).

\section{Vertical displacements on $X$ - and Y-lines (period 2)}

Vertical displacements of YSMPs are plotted against the relative position of the cutter-head $\left(x_{\mathrm{f}}\right)$ to the main Y-line during the passage of TBM1 in Fig. 8(a). Vertical settlements started to develop when the cutter-head was about $14 \mathrm{~m}$ in front of the instrument line $\left(x_{\mathrm{f}}=-14 \mathrm{~m}\right.$ or $\left.-0 \cdot 4 z_{0}\right)$. When the cutter-head was directly beneath the Y-line, a surface settlement of $1.7 \mathrm{~mm}$ was measured at YSMP11 (above the tunnel centre-line), or about $30 \%$ of the total maximum settlement $(5.6 \mathrm{~mm})$ measured in the short term. Immediate settlements essentially ceased when the TBM1 cutter-head had passed $35 \mathrm{~m}$ beyond the main line $\left(x_{\mathrm{f}}=35 \mathrm{~m}\right.$ or $\left.1 \cdot 0 z_{0}\right)$. Fig. 8(b) depicts the development of the transverse settlement trough on the main Y-line SMPs as TBM1 passed, the maximum settlement was always at the location of the TBM1 centre-line, that is, either at YSMP11 $(y=0 \mathrm{~m})$ or YSMP12 $(y=2.5 \mathrm{~m})$.

The locations of SMPs Y12A, Y13A and Y14A were offset from the main line to avoid a tree root. As a consequence there is a clear step within the developing settlement profiles (e.g. when $x_{\mathrm{f}}=1.5 \mathrm{~m}$ and $9.8 \mathrm{~m}$ ), which closed once TBM1 


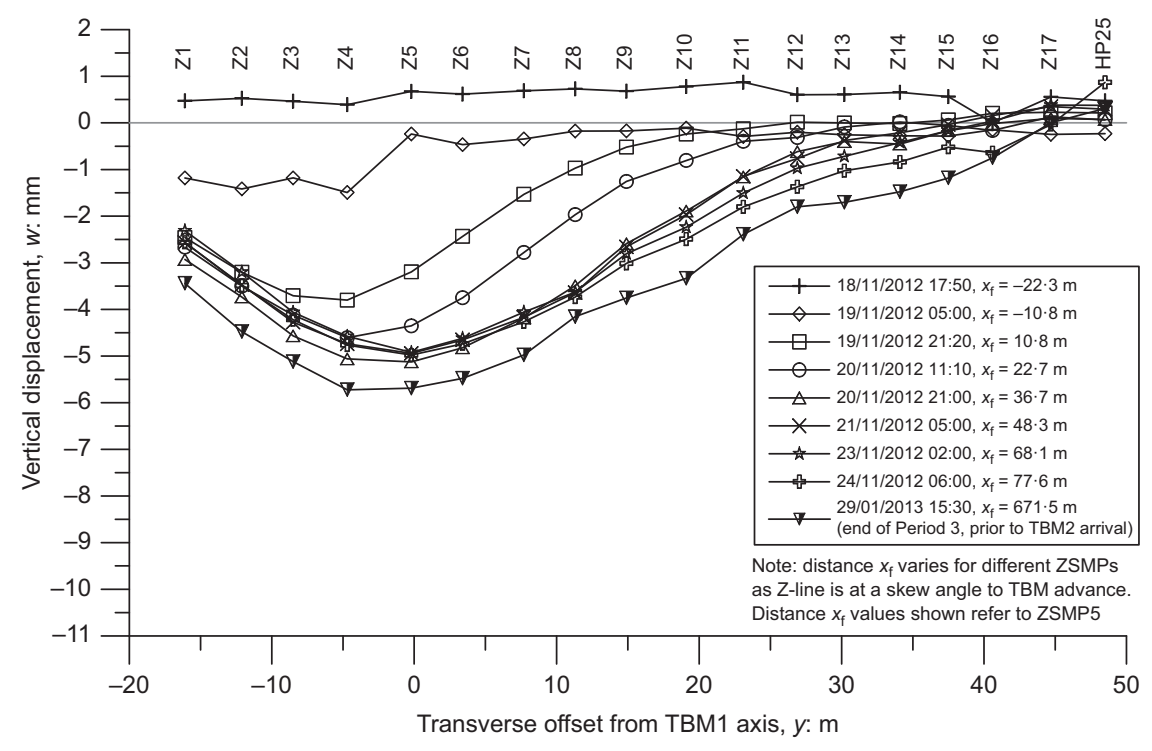

(a)

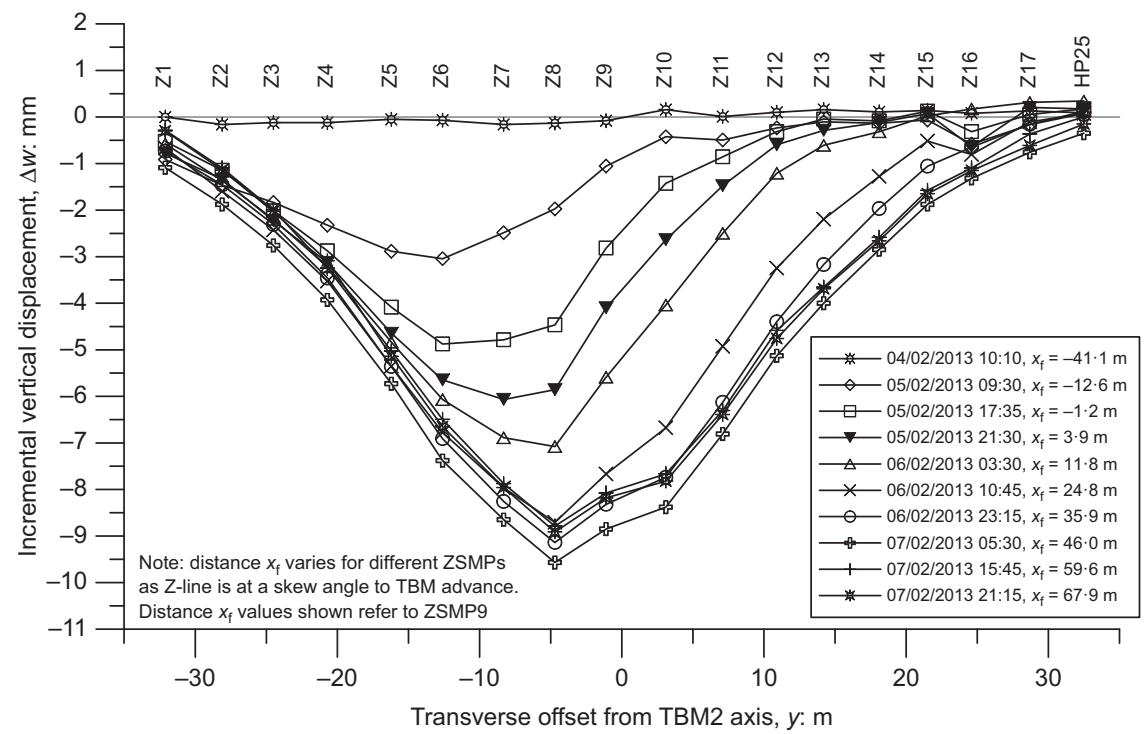

(b)

Fig. 7. Development of settlement troughs for Z-line SMPs during passage of (a) TBM1 (period 2) and (b) TBM2 (period 4; note: incremental settlement troughs shown)

had passed. For similar reasons SMPs Y21 to Y24 were also offset from the main line with Y20 and Y21 being at the same distance $y$ (Fig. 4(a)), but as these points were further from the centre-line of TBM1 the effect is not so noticeable (Fig. 8(b)).

Similar overall responses to those on the Y-line were observed on the greenfield X-line as shown in Figs 8(c) and $8(\mathrm{~d})$. At this location the maximum settlement was $8.3 \mathrm{~mm}$ and $30 \%$ of it had developed when the cutter-head was directly beneath the line.

A clearer picture of the surface movements emerges when the results are normalised by dividing by the relevant maximum observed settlement. The normalised longitudinal settlement troughs that developed above the TBM centre-line position during TBM1 passage are shown in Fig. 9(a). The normalised settlements $\left(w / w_{\max }\right)$ for extensometer HP20 (Fig. 4(a)), YSMP11, XSMP15 and ZSMP5 (where the maximum settlements occurred) lie within a well-defined narrow band with surface settlements confined to a cutter-head distance range of $-15 \mathrm{~m}<x_{\mathrm{f}}<35 \mathrm{~m}$. Such a well-defined range is remarkable when it is considered that the four measurement points are spread over a horizontal distance of more than $150 \mathrm{~m}$, one being in Bayswater Road (ZSMP5) where the Central Line tunnels could have an influence and the other in Hyde Park greenfield ground (XSMP15). This suggests a consistent contribution of surface settlement from the actions of the EPBM tunnelling. Longitudinal trough length factors, $i_{x}$, determined from these normalised displacement plots range from $11.2 \mathrm{~m}$ to $12.6 \mathrm{~m}$ for the four monitoring points, with corresponding trough length parameters $\left(K_{x}\right)$ ranging between $0 \cdot 32$ and $0 \cdot 37$. The normalised vertical displacements $\left(w / w_{\max }\right)$ directly above the cutterhead (i.e. when $x_{\mathrm{f}}=0 \mathrm{~m}$ ) ranged from $24 \%$ to $36 \%$, which is somewhat larger than the range of $5-20 \%$ reported by Withers (2001) for the EPBM tunnelling in the Lambeth Group and Thanet Sands for JLE construction.

The normalised transverse settlement troughs measured along the X-line and Y-line SMPs and the main line of rod extensometer reference heads (close to the Y-line) at the end of the TBM1 passage are shown in Fig. 9(b). Note that negative $y$ distances relate to the southern half of the trough in accordance with the sign convention given in the section 


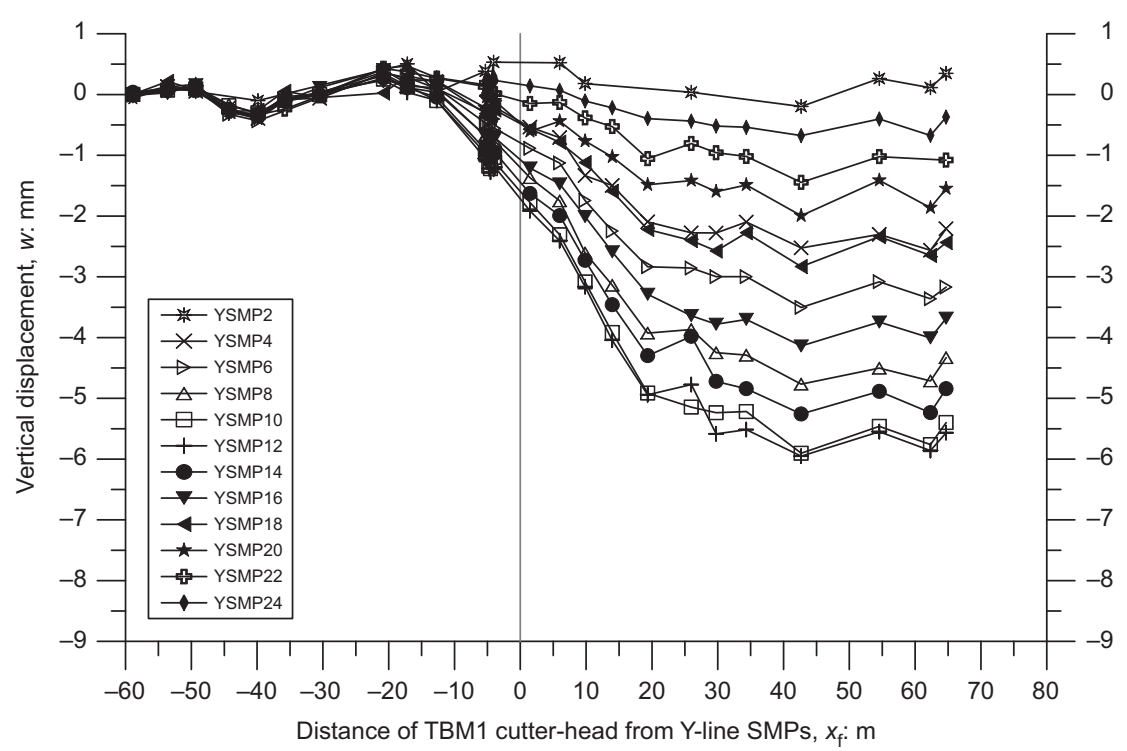

(a)

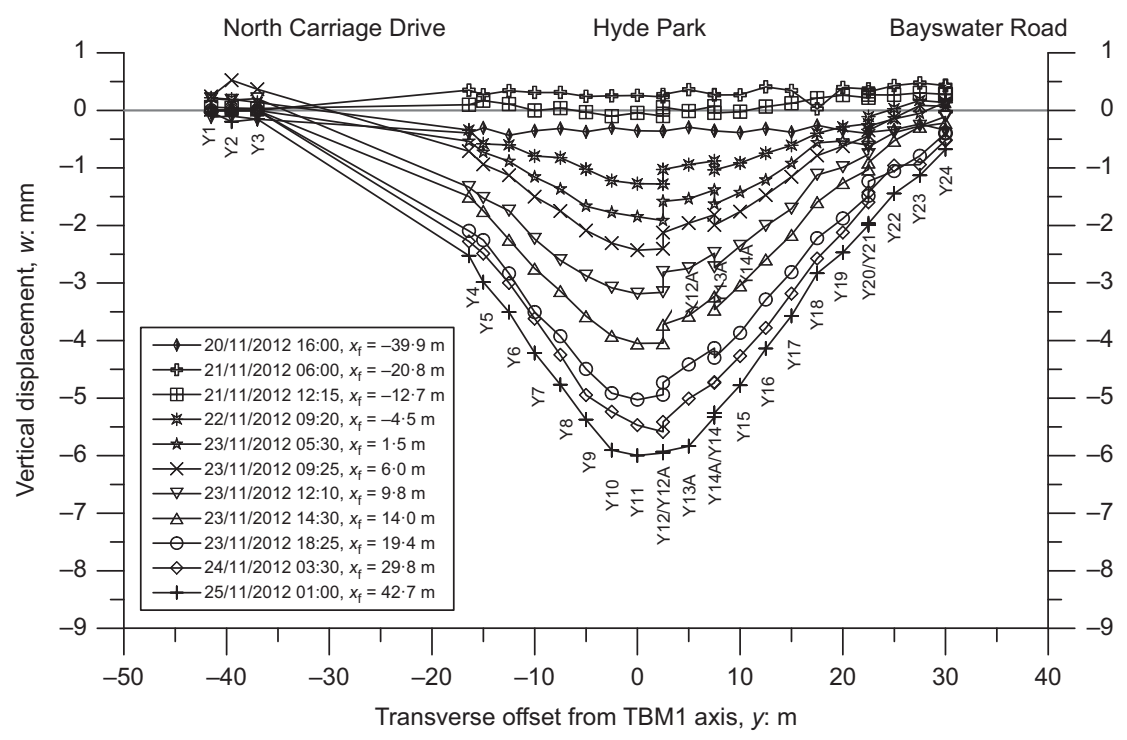

(b)

Fig. 8. Ground response during passage of TBM1 (period 2): (a) vertical displacements of Y-line SMPs plotted against cutter-head position; (b) development of settlement troughs for Y-line SMPs; (c) vertical displacements of X-line SMPs plotted against cutter-head position; (d) development of settlement troughs for X-line SMPs (continued on next page)

entitled 'Surface monitoring results'. It can be seen that the three normalised settlement troughs are broadly similar in shape except for the northern part of the X-line at a distance greater than $20 \mathrm{~m}$ from the TBM1 axis, where the settlements are significantly greater than for the Y-line and extensometer reference heads.

The detailed characteristics of the transverse troughs can be reviewed by comparing the trough width factors $\left(i_{y}\right)$ and volume losses $\left(V_{\mathrm{L}}\right)$ derived from the measurements. The former are derived by plotting the logarithm of normalised displacements $\left(\ln \left(w / w_{\max }\right)\right)$ against the square of the normalised transverse offset distances $\left(\left(y / z_{0}\right)^{2}\right)$ as shown in Fig. 10 for the X-line SMPs. If the trough is of a Gaussian form, the data, when plotted in this way, should lie on a straight line passing through the origin. In the case of the X-and Y-line SMPs and the extensometer line, only data points closer to the TBM axis (generally $\ln \left(w / w_{\max }\right)>-1 \cdot 0$, or $w / w_{\max }>0 \cdot 36$ ) form a straight line, indicating that the measured displacements near the ends of the troughs do not exactly follow the idealised Gaussian curves. For the purpose of comparing the Gaussian approximations, lines are only fitted through the measurement points closer to the TBM centre-line $\left(w / w_{\max }>0 \cdot 36\right)$. The Gaussian curves with the $i_{y}$ values so determined are plotted together with the measured displacement values for the X-line and Y-line SMPs and the main extensometer line in Figs 11(a)-11(c). The $i_{y}$ values for the southern- and northern-half troughs have been determined separately.

The symmetry of the settlement troughs is assessed by comparing the trough width factors between the southernand northern-half troughs. It can clearly be seen from Fig. 11(a) that, with almost the same $i_{y}$ values $(15 \mathrm{~m})$ or $K_{y}$ values $(0 \cdot 44)$ for both halves, the settlement trough for the $\mathrm{X}$-line was essentially symmetric. This agrees with the expected tunnelling-induced greenfield ground response. The reason for the group of points on the far northern-half trough (XSMP25 to XSMP30, see Fig. 4(b)) lying beneath the fitted Gaussian curve is not understood. It is this same group of points that are at a considerable offset from the straight line in Fig. 10. A possible cause might be the North Carriage Drive, although it did not have the same effect on 


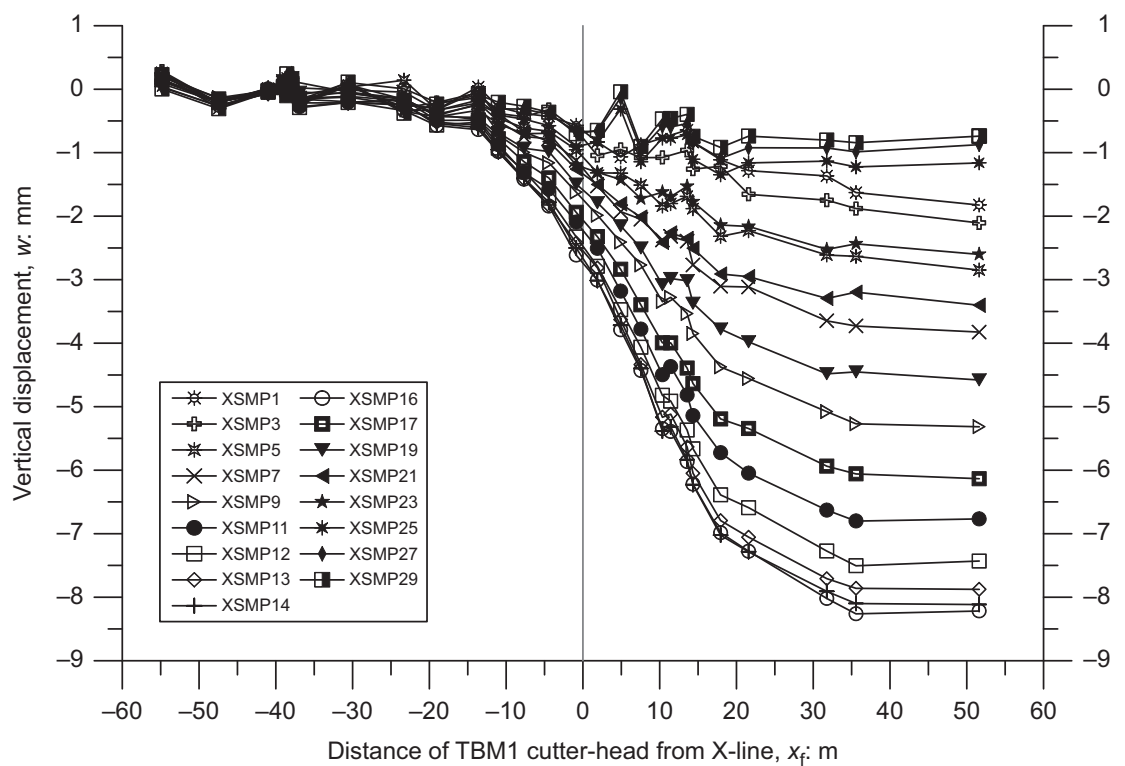

(c)

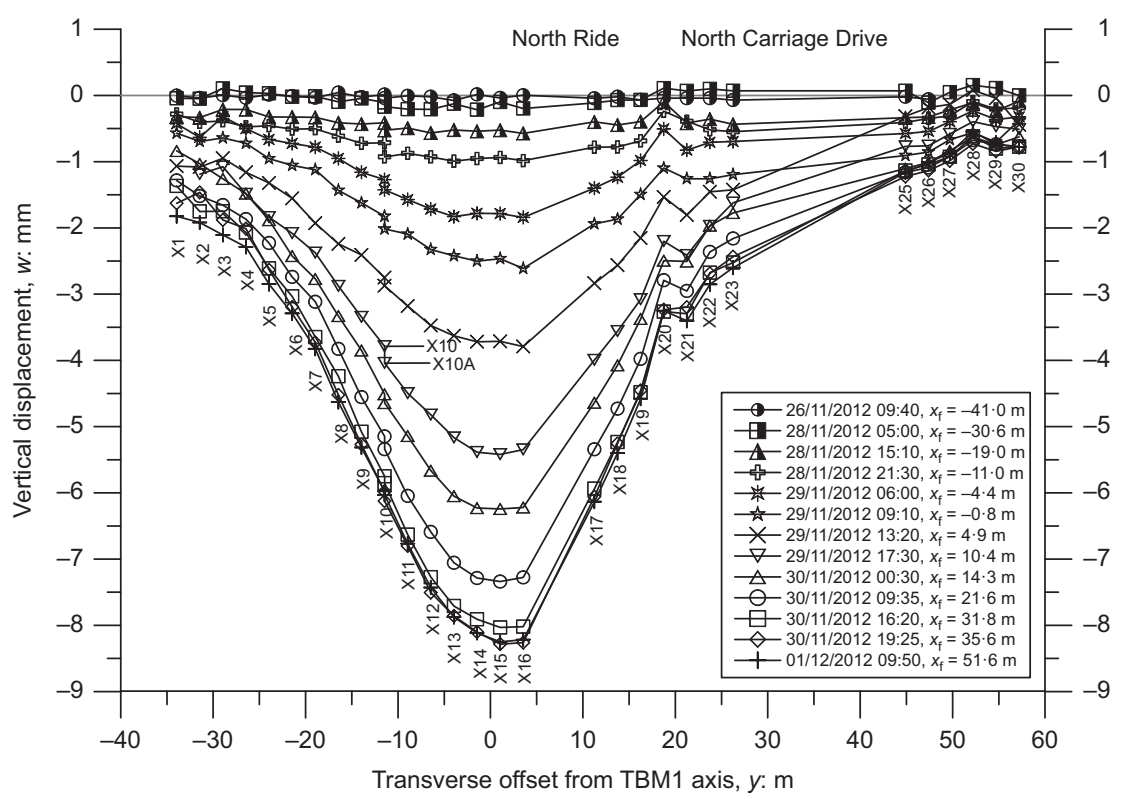

(d)

Fig. 8. Continued

the Y-line, as will be seen shortly. In hindsight it would have been useful to have installed some levelling studs across the road surface to understand its overall response (even if readings were only taken occasionally).

In the case of both the Y-line SMPs and the main extensometer line, the northern-half troughs had larger $i_{y}$ values than the southern counterparts, as shown in Figs 11(b) and 11(c), possibly reflecting the influence of the Central Line tunnels on the surface settlements. The influence of the pre-failure soil stiffness and stress history of the ground on tunnelling-induced surface settlements, investigated using numerical analysis, has been reported in the literature (e.g. Addenbrooke et al., 1997; Grammatikopoulou et al., 2008). Construction of the Central Line tunnels more than a century ago and the consequent change of the stress regime in the surrounding ground would have reduced the soil stiffness and therefore led to the wider tunnelling-induced surface settlement troughs measured on the northern halves of the lines (closer to the existing tunnels), compared with those measured in greenfield ground to the south.
The ratios of trough width parameter to trough length parameter $\left(K_{y} / K_{x}\right)$ determined for the three surface monitoring lines were found to be greater than unity (1.0 to $1 \cdot 3)$, and agree with findings from other London Clay sites such as the JLE project (Nyren, 1998) and CTRL project (Selemetas, 2005; Wongsaroj et al., 2006).

The overall volume loss values are obtained from averaging the values for the two half-troughs and, although not determined from the actual area under the transverse settlement profile, give an indication of the effectiveness of the tunnel construction method in controlling the ground loss. The overall volume loss values relating to the Y-line SMPs and the main extensometer line reference heads are consistent $(0 \cdot 44 \%$ and $0.48 \%$ ), while that for the X-line SMPs is considerably greater $(0 \cdot 78 \%)$. As there are negligible differences in either the stratigraphy or the EPBM operation variables between the Y- and $\mathrm{X}$-lines, the lower volumes losses at the $\mathrm{Y}$-line might suggest that the presence of the Central Line tunnels may have inhibited overall ground movements from the Crossrail tunnel construction (already evident in the asymmetry of the settlement 


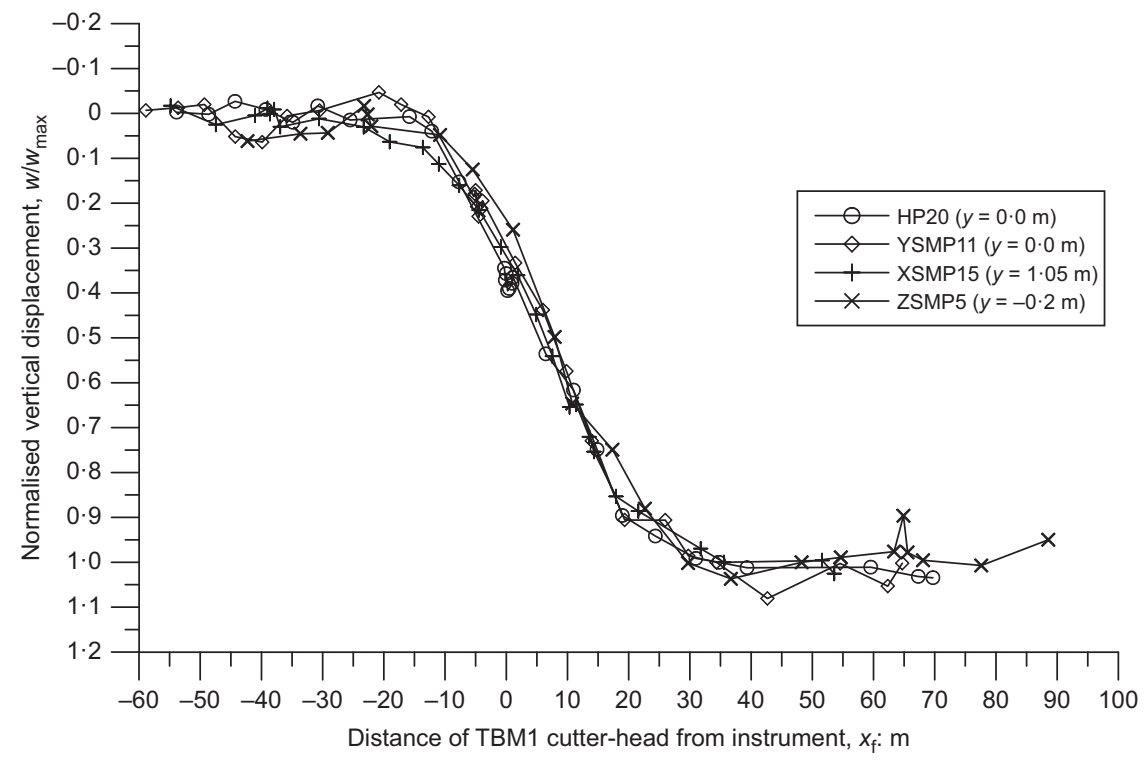

(a)

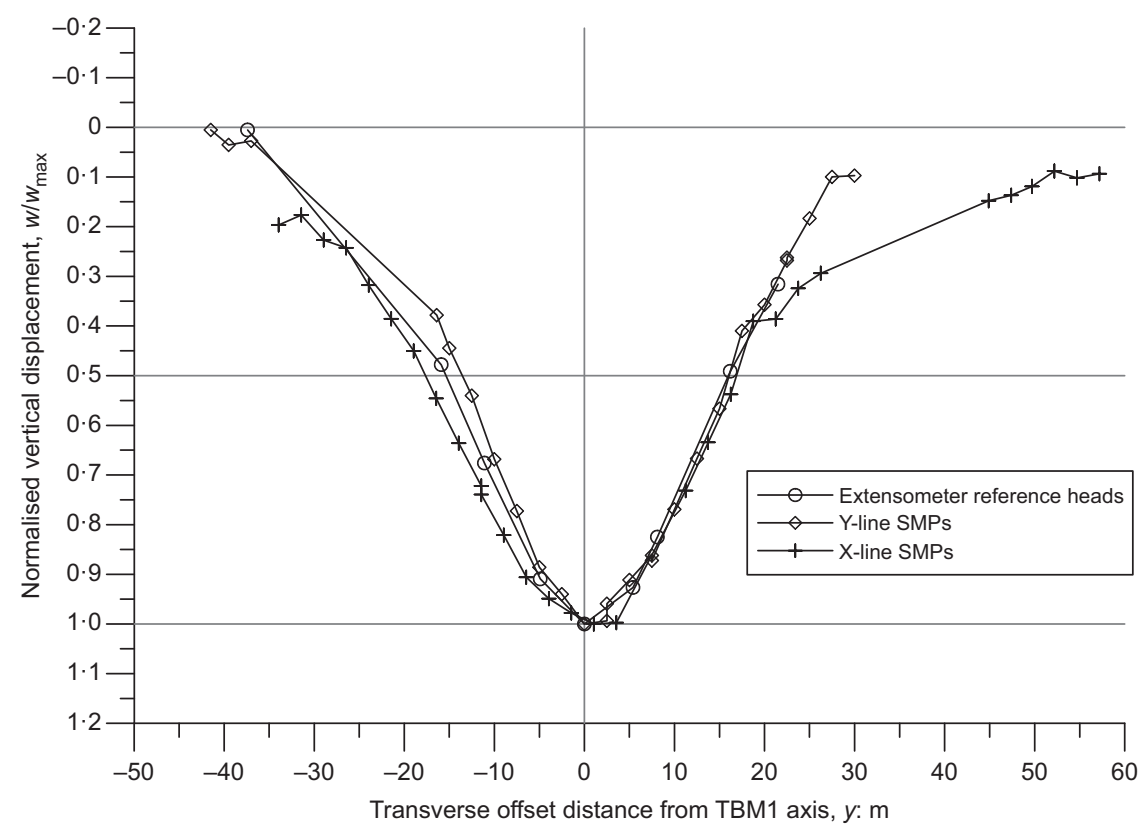

(b)

Fig. 9. (a) Longitudinal profiles of normalised surface vertical displacements during passage of TBM1 (period 2); (b) transverse profiles of normalised surface vertical displacements after passage of TBM1 (period 2)

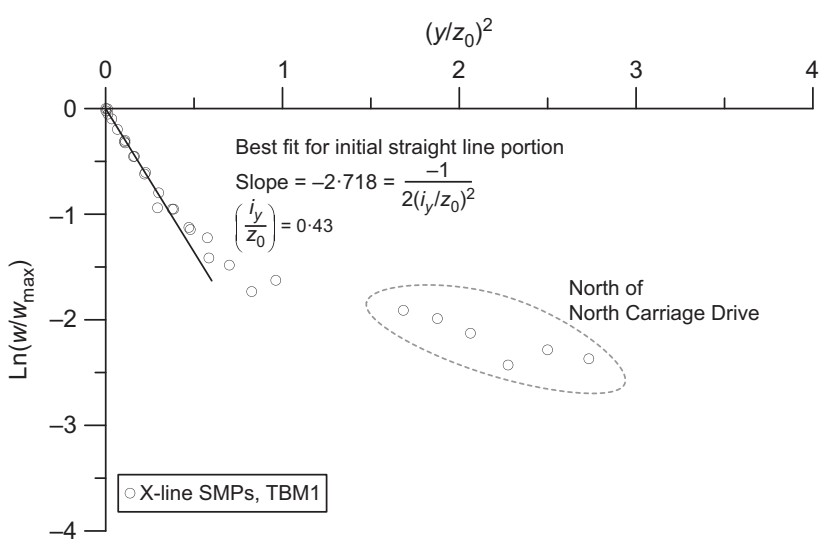

Fig. 10. Determination of trough width parameters by plotting $\ln \left(w / w_{\text {max }}\right)$ against $\left(y / z_{0}\right)^{2}$ troughs). Additionally, in numerically modelling the ground response to tunnel construction at Hyde Park (but without the presence of the Central Line tunnels), Avgerinos (2014) found that the ground heaved at $50 \mathrm{mbgl}$ at the location of HP21 (the point initially used as the datum for the field measurements on the Y-line). This would result in apparently greater vertical displacements than in reality. The measurements were reanalysed in relation to another datum (HP24 at $40 \mathrm{mbgl}$ ) which, although shallower, is further from the zone of tunnel influence. The results presented are relative to this more stable datum. In making this further adjustment, values of settlement and volume loss become even smaller than those based on HP21 and therefore are even less than those determined for the $\mathrm{X}$-line. This factor, concerning the stability of the datum used, might therefore also contribute to the differences in volume loss between the two sections, as well as the presence of the Central Line tunnels. Values of various characteristics relating to the longitudinal and transverse vertical displacement profiles at the four surface monitoring lines are summarised in Table 1. 


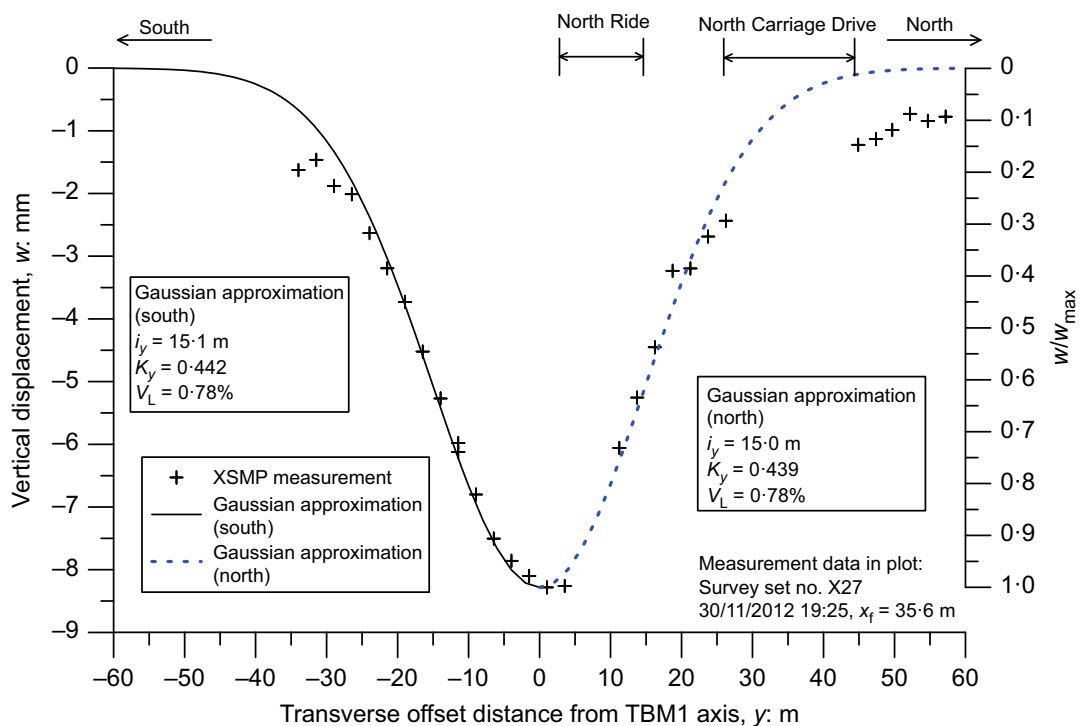

(a)

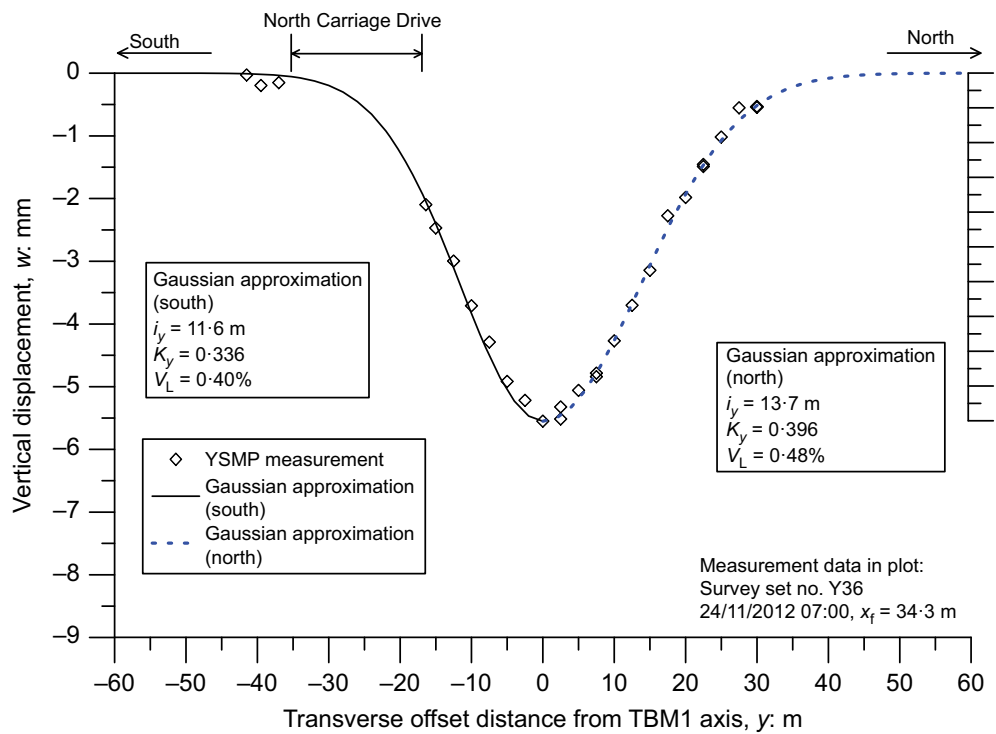

(b)

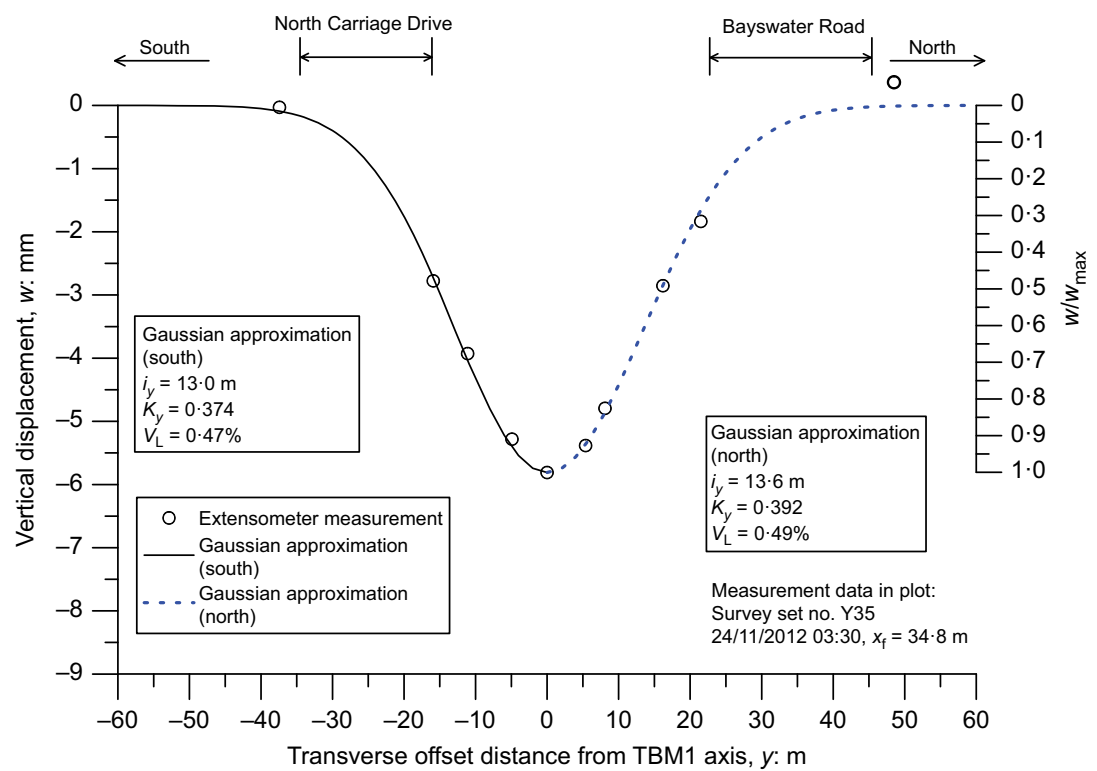

(c)

Fig. 11. Gaussian approximation of surface vertical displacements measured at the end of passage of TBM1 (period 2) for: (a) X-line SMPs; (b) Y-line SMPs; (c) extensometer reference heads 


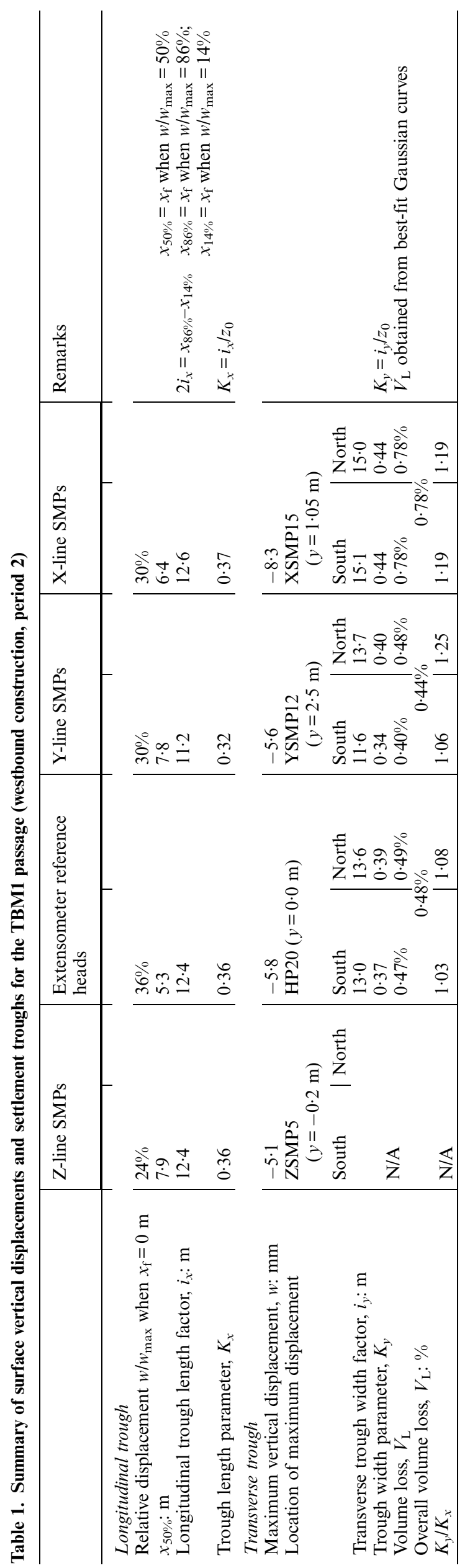

Vertical displacements on $X$ - and $Y$-lines (period 4)

Similar trends of vertical displacements were observed as TBM2 passed beneath the site. Normalised longitudinal and transverse profiles, based on incremental vertical displacements of the X-and Y-line SMPs and the main extensometer line, are shown in Figs 12(a) and 12(b), respectively.

The development of the longitudinal profiles of normalised incremental settlements for HP23, YSMP17, XSMP19 (located at or near the TBM2 centre-line) agree well with each other (Fig. 12(a)), as observed during the passage of TBM1. For ZSMP9, above the TBM2 centre-line, there is a slight deviation from the other lines after the cutter-head had passed the instrument line. This deviation could reflect the effect of the Central Line tunnels 'shielding' the Z-line SMPs from the surface settlement, although the same effect was not observed for the passage of TBM1.

Incremental surface settlements occurred within the cutterhead distances of $-20 \mathrm{~m}<x_{\mathrm{f}}<35 \mathrm{~m}$ for the $\mathrm{X}$ - and Y-line and extensometer reference heads. The trough length factors $\left(i_{x}\right)$ derived from the measurements are broadly consistent and range from $12.7 \mathrm{~m}$ to $14.8 \mathrm{~m}$, with corresponding trough length parameters $\left(K_{x}\right)$ being between $0 \cdot 37$ and 0.43 . These are slightly larger than the values determined from the TBM1 case, indicating slightly longer longitudinal settlement troughs. The normalised incremental vertical displacements $\left(\Delta w / \Delta w_{\max }\right)$ directly above the TBM 2 cutter-head were $38-39 \%$, which is larger than the case for the passage of TBM1. This implies that a higher proportion of surface ground settlement occurred in front of the TBM2 cutterhead, compared with the TBM1 case. This may be explained by the ground ahead of TBM 2 being softened by the first tunnel construction.

The normalised incremental transverse settlement troughs measured after the passage of TBM2 are shown in Fig. 12(b). The southern-half troughs are wider than the northern-half troughs for all the three monitoring lines. This is most likely to result from the ground on the southern side being disturbed and softened by the passage of TBM1. The effect of the passage of TBM1 appears to be greater than the effect of the presence of the existing Central Line tunnels and therefore dominates the shape of the incremental settlement troughs. This is reasonable considering the closer proximity, larger diameter and much more recent construction activity.

Best-fit Gaussian curves for the incremental vertical displacements for the $\mathrm{X}$ - and Y-line SMPs and main extensometer line are compared in Figs 13(a)-13(c). The southern-half troughs of incremental settlement (i.e. the side where TBM1 was located) have larger trough width parameter $K_{y}$ values than the northern-half troughs. Corresponding $K_{y}$ values are quite consistent $\left(0.42<K_{y}<0.47\right.$ for southern-half and $0.29<K_{y}<0.33$ for northern-half troughs), irrespective of whether the monitoring lines are in greenfield ground (X-line) or near the Central Line tunnels (Y-line), confirming the dominant effect of the first tunnel construction (TBM1) on the subsequent ground response. As with the X-line SMP results from period 2, incremental vertical displacements at larger transverse offsets (i.e. further away from the TBM2 centre-line) have a larger downward magnitude than would be predicted by the Gaussian curves fitted through the data points closer to the TBM centre-line. An alternative Gaussian curve that passes through these data points, but not those close to the centre-line, is also given in Fig. 13(a).

Similar to the case of the TBM1 passage, the ground beneath the X-line SMPs had a greater overall volume loss $(1 \cdot 18 \%)$ than that beneath the Y-line SMPs $(0 \cdot 82 \%)$ and main extensometer line $(0 \cdot 82 \%)$ due to TBM2 passage. Measurements at all three monitoring lines indicate that larger incremental volume losses were induced by TBM2 


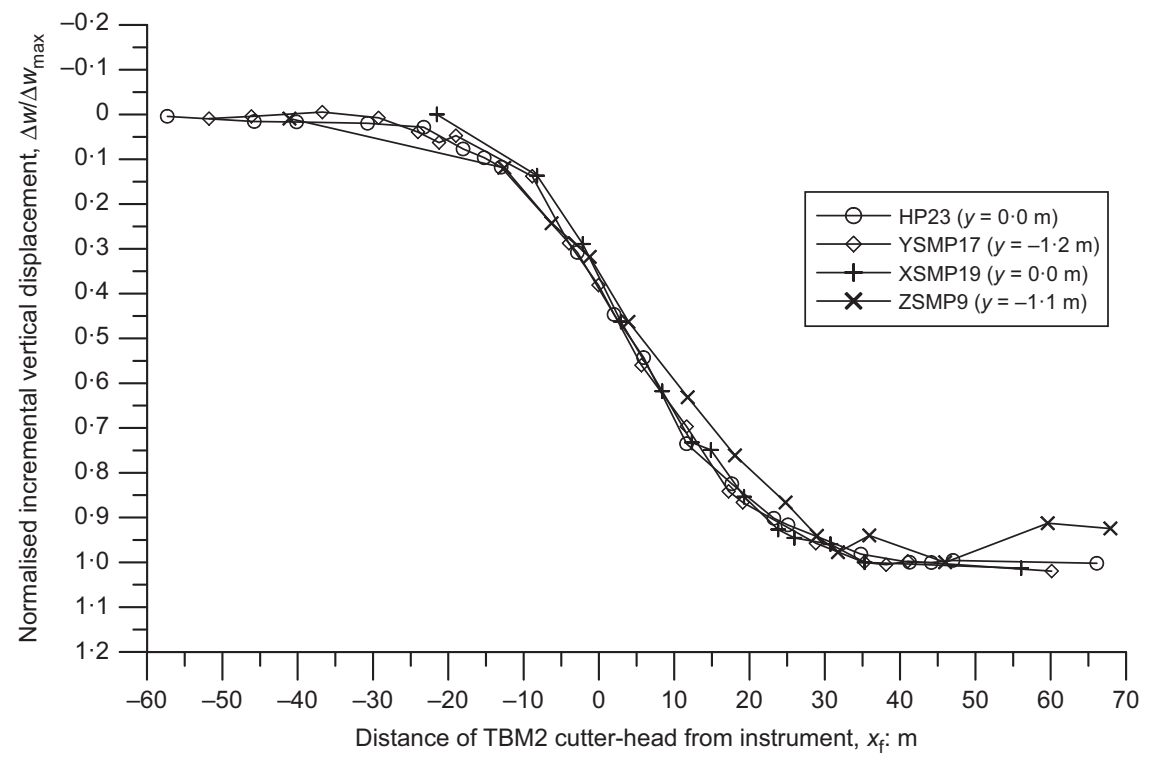

(a)

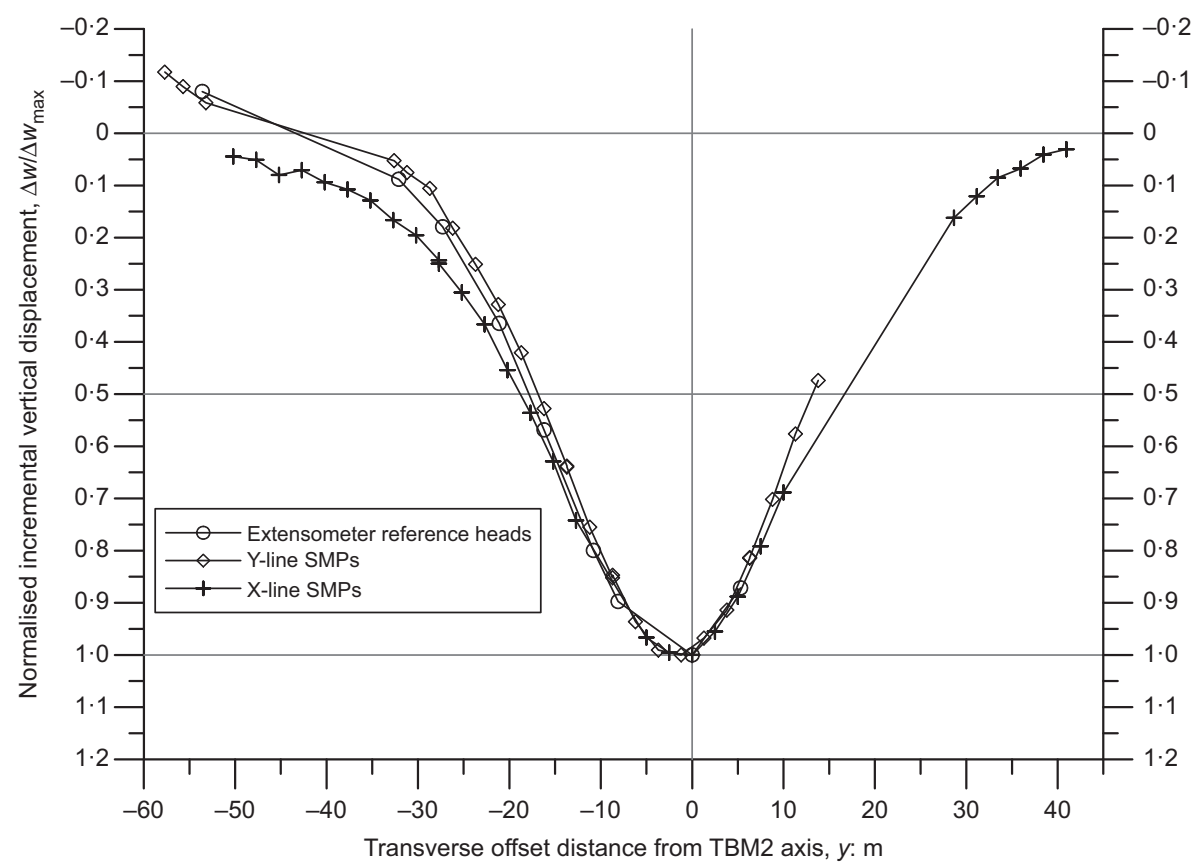

(b)

Fig. 12. (a) Longitudinal profiles of normalised incremental surface vertical displacements during passage of TBM2 (period 4). (b) Transverse profiles of normalised incremental surface vertical displacements after passage of TBM2 (period 4)

compared with TBM1. As the EPBM operation variables such as the face pressure, tail grout pressure and tail grout volume were similar for TBM1 and TBM2 (discussed later), this confirms once again that the higher volume loss induced by TBM 2 results from the ground being softened by the first tunnel construction.

Various characteristics relating to the longitudinal and transverse incremental vertical displacement profiles measured along the four lines are summarised in Table 2.

\section{Comparison with previous surface settlement case studies}

The responses at Hyde Park are now compared with those from instrumented sites for: $(a)$ the JLE project at St James's Park where $4.85 \mathrm{~m}$ dia. tunnels were constructed by openface shield TBMs (Nyren, 1998); and (b) the CTRL project at Dagenham where $8.16 \mathrm{~m}$ dia. tunnels were constructed by EPBMs (Selemetas, 2005; Standing \& Selemetas, 2013). The first site, being also located in central London, shares a similar geology with the Hyde Park site. The first westbound tunnel at St James's Park was constructed at a depth $\left(z_{0}=31.0 \mathrm{~m}\right)$ comparable to the Hyde Park Crossrail tunnels $\left(z_{0}=34.6 \mathrm{~m}\right)$. At the second site at Dagenham, slightly larger diameter tunnels than those for Crossrail were constructed using comparable EPBMs, with applied face and tail grout pressures similar to those of the EPBMs beneath Hyde Park. However, the CTRL tunnels at Dagenham were constructed at a shallower depth $\left(z_{0}=18.9 \mathrm{~m}\right)$ with a significantly thinner overburden and cover of London Clay.

The development of the longitudinal profiles of normalised surface settlements above the centre-line of the first TBM passing beneath each of the three sites is shown in Fig. 14. When the cutter-head was directly below the monitoring line, about $30 \%$ of the total settlement had occurred for the 


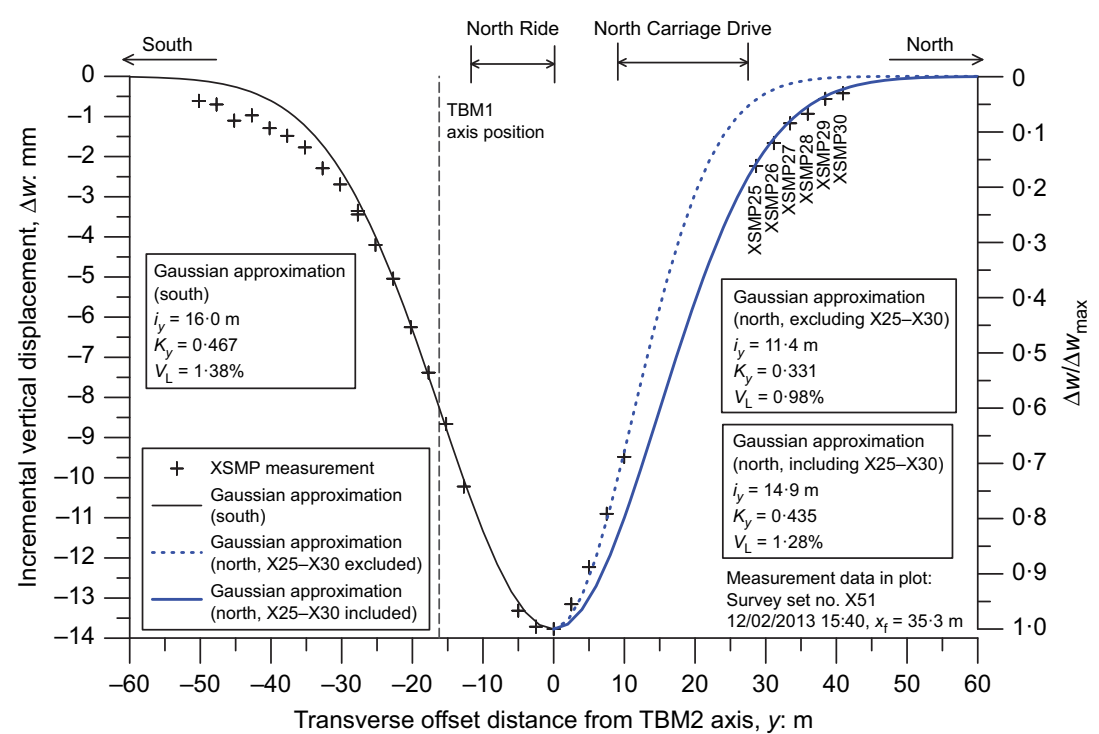

(a)

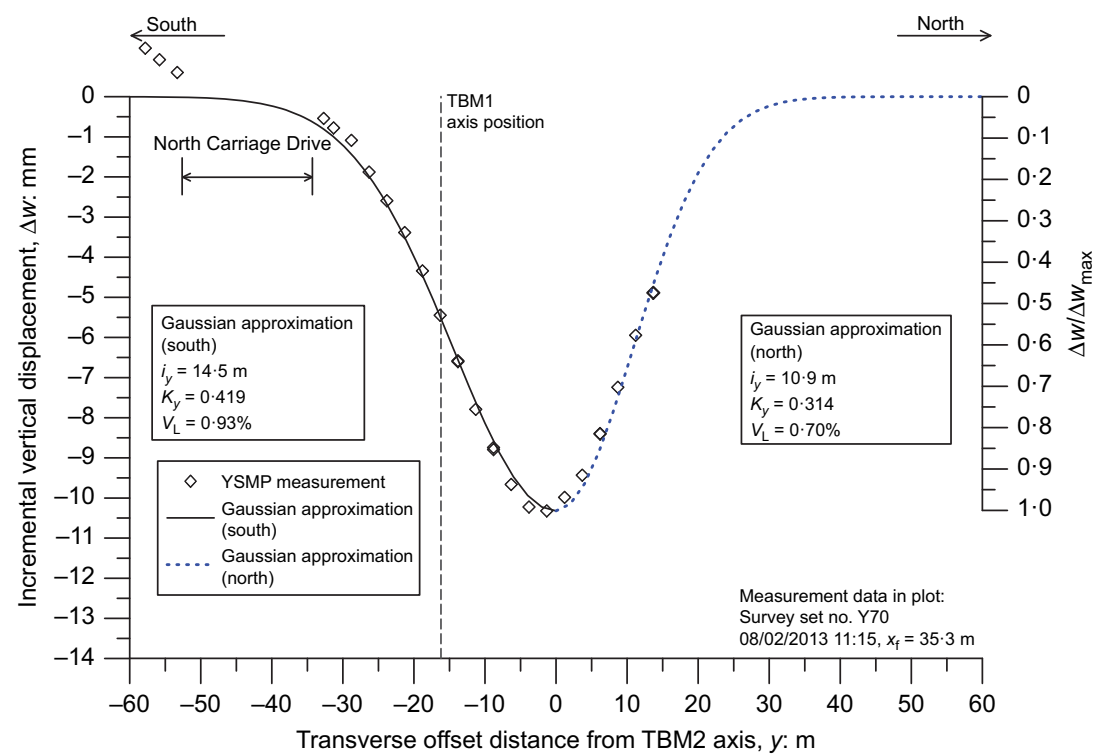

(b)

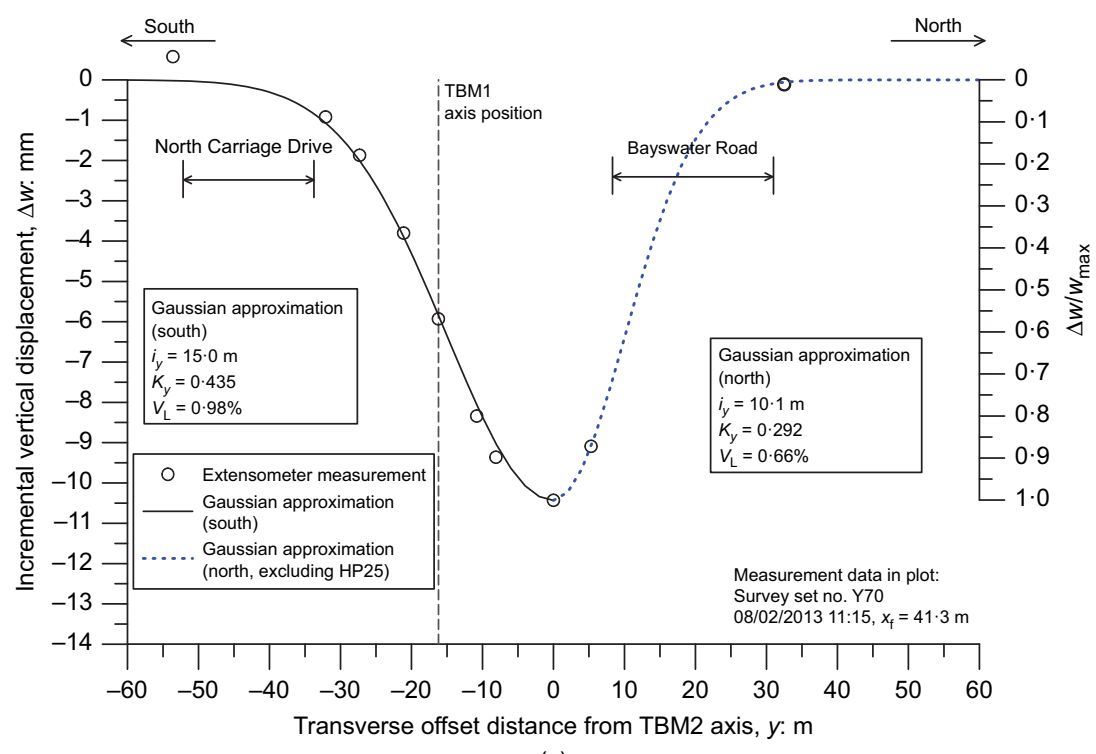

(c)

Fig. 13. Gaussian approximation of incremental surface vertical displacements measured at the end of TBM2 passage (period 4) for: (a) X-line SMPs; (b) Y-line SMPs; (c) extensometer reference heads 


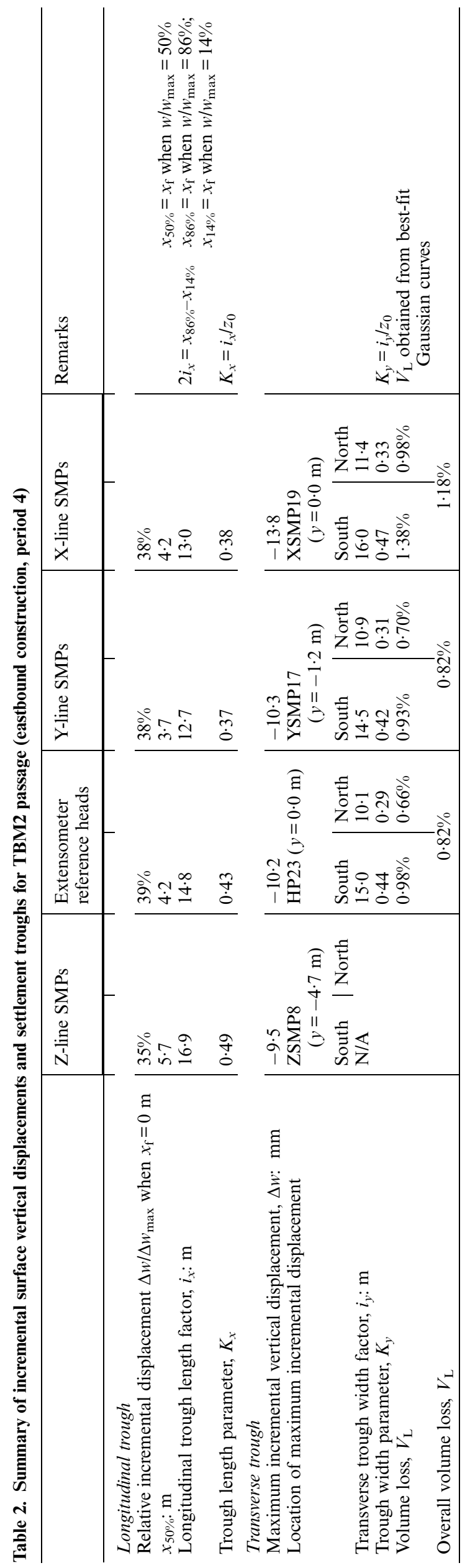

EPBM tunnelling (Hyde Park and Dagenham), whereas about $50 \%$ of the total settlement had occurred for the openface shield tunnelling (St James's Park). This confirms that with open-face shield excavation a greater proportion of surface settlement originates from the ground movement in front of the shield, which is countered by the provision of face pressure with EPBMs. For EPBMs, greater proportions of overall ground movement originate from radial deformations around the shield body (especially when it is tapered) and tail void closure.

The forms of the normalised longitudinal surface settlement profiles for the Hyde Park and St James's Park sites are similar, even though the tunnels were built using different construction methods (i.e. open-face shield as opposed to EPBM). Values of trough length parameter $\left(K_{x}=i_{x} / z_{0}\right)$ determined from fitting cumulative probability function curves through these profiles are very close $(0 \cdot 31$ and $0 \cdot 33)$. However, the shapes of the profiles for Hyde Park and Dagenham are very different, despite the tunnels at both sites being constructed by comparable EPBMs. The ground surface at Dagenham experienced smaller settlement and even upward displacements (from face pressure and tail-skin grouting) when the TBM shield body was passing, followed by a more rapid settlement as the TBM tail progressed beyond the monitoring line. This reflects the fact that the tunnel at Dagenham was constructed at a shallower depth with the axis-level overburden pressure $(\approx 340 \mathrm{kPa})$ roughly half that at Hyde Park $(\approx 650 \mathrm{kPa})$, while at both sites the measured tail grout pressures were similar (between 150 and $200 \mathrm{kPa}$ ).

The normalised transverse surface settlement profiles for the three sites are presented in Fig. 15. The three profiles agree well for the range of measurements with $w / w_{\max }>0 \cdot 4$, close to the TBM centre-line position, and can be approximated by one single Gaussian distribution with $K_{y}=0.43$. This confirms that the trough width parameters of the immediate surface settlement trough are independent of the tunnelling method but dependent mainly on the type of ground (O'Reilly \& New, 1982). The deviation at larger offset distances of the measured surface settlements from the approximated Gaussian curve is larger at Hyde Park than the other two sites. Currently no definite reason has been identified for this but, as discussed earlier, a plausible reason could be the presence of the road (North Carriage Drive) where the relatively stiff sub-grade and sub-base layer may have influenced the surface ground response.

The surface settlement trough width factors $\left(i_{y}\right)$ and trough width parameters $\left(K_{y}\right)$ determined from the three sites are plotted against the tunnel depths $\left(z_{0}\right)$ in Figs 16(a) and 16(b), respectively. Data from recent case histories along with those reported by O'Reilly \& New (1982) and Mair \& Taylor (1997) are presented in the same figure. Tunnel depths are less than $30 \mathrm{~m}$ in most of the earlier cases: the Hyde Park and St James's Park results contribute deeper tunnel cases to the database. The $K_{y}$ values for all the deeper tunnels fall within the range $0 \cdot 40<K_{y}<0 \cdot 45$. The values of $i_{y}$ and $K_{y}$ from Hyde Park are marginally smaller than those determined from the O'Reilly \& New (1982) relationship, confirming that deeper tunnels have slightly narrower surface settlement troughs than shallower tunnels.

In order to investigate potential relationships between the volume loss and face pressure for the three instrumented greenfield sites, the measured volume losses are plotted against the ratio of the TBM face pressure to overburden pressure, as shown in Fig. 17. The limited case history data presented in the figure suggest a trend of decreasing volume loss with increasing face pressure ratio for tunnelling in London Clay. Other factors such as the geology and tunnelling procedure are also likely to influence the volume loss. 


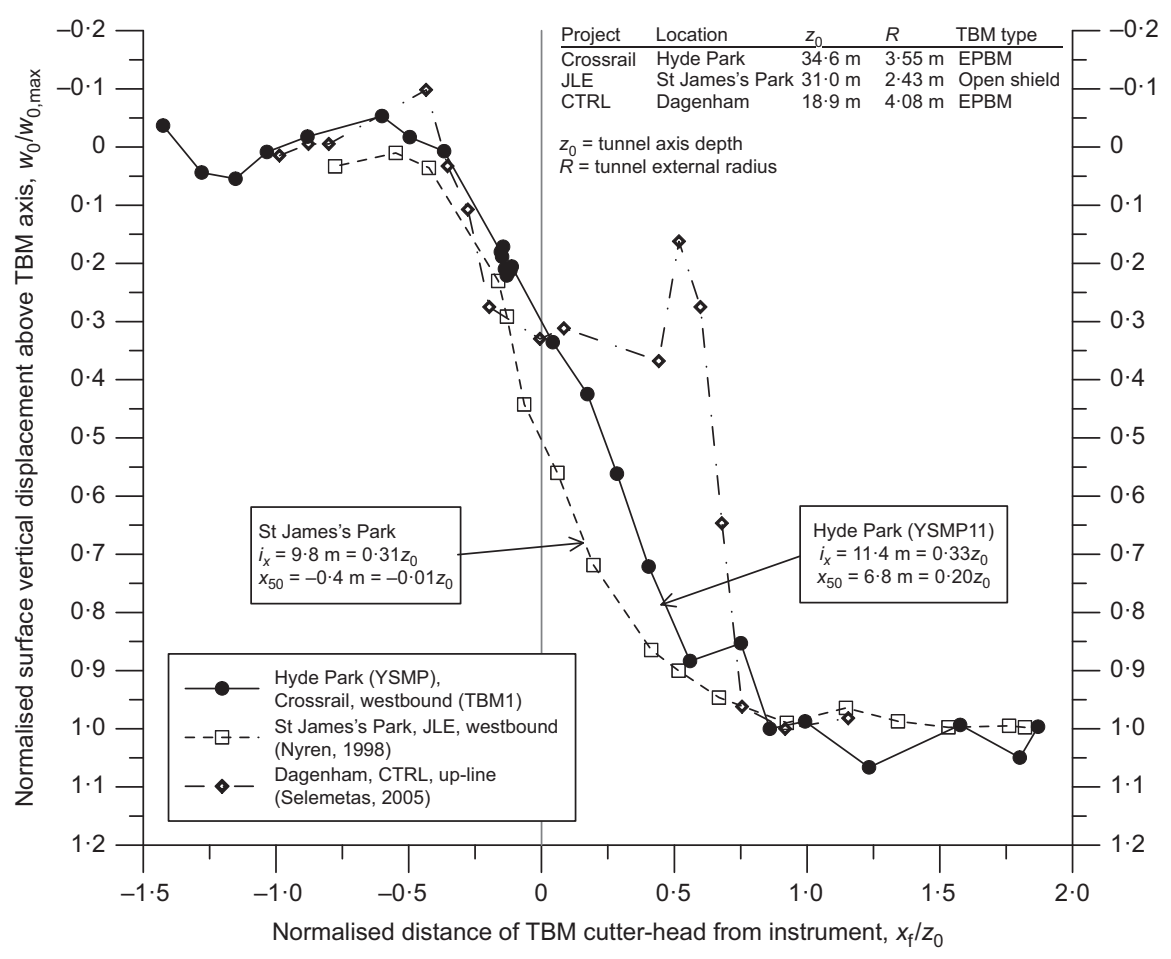

Fig. 14. Longitudinal profiles of normalised surface vertical displacements measured at three instrumented sites in London

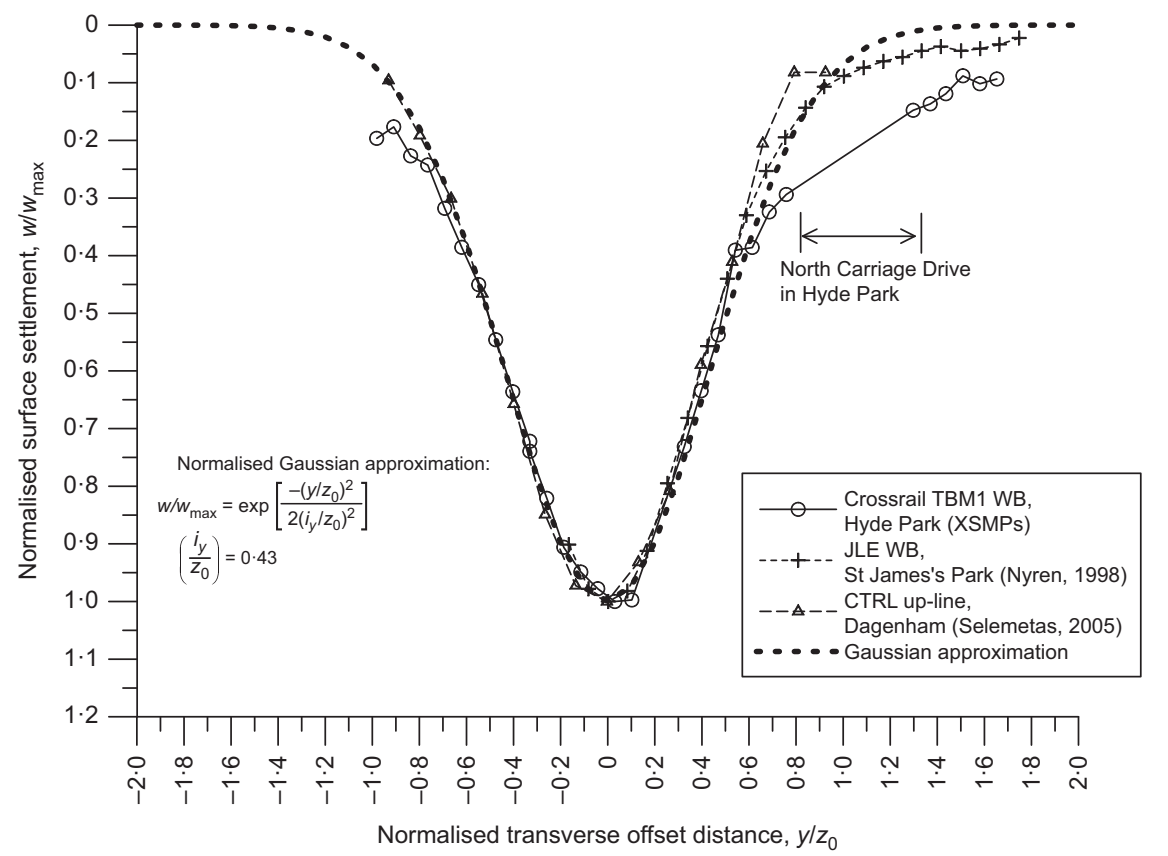

Fig. 15. Transverse profiles of normalised surface vertical displacements measured at three instrumented sites in London

In the case of the JLE open-face tunnelling under St James's Park, the short-term greenfield volume loss measured from surface monitoring after the first tunnel construction was found to range from $3 \cdot 3 \%$ to $3 \cdot 5 \%$ south of the lake, and from $1 \cdot 5 \%$ to $2 \cdot 0 \%$ north of the lake (Standing $\&$ Burland, 2006). It should be noted that different tunnelling procedures, involving different excavation sequences and lengths of unsupported tunnel heading in front of the shield, were adopted on either side of the lake. Another important contributing factor to the difference in the measured volume losses was that the upper $4.5 \mathrm{~m}$ of the London Clay was found to have been eroded south of the lake. The two ranges of volume loss south and north of the lake are shown in Fig. 17 (as an open-face shield was used the face pressure ratio is zero).

For the CTRL tunnelling under the Dagenham instrumented site, Standing \& Selemetas (2013) reported a shortterm volume loss of $0 \cdot 2 \%$ measured from the surface monitoring after the first tunnel construction. The face pressure was about $200 \mathrm{kPa}$ or about $44 \%$ of the overburden pressure at the tunnel axis level. By comparison, for the Crossrail tunnelling under Hyde Park, the short-term greenfield volume losses measured at the X-line and Y-line SMPs are $0.78 \%$ and $0.44 \%$, respectively. The face pressure 


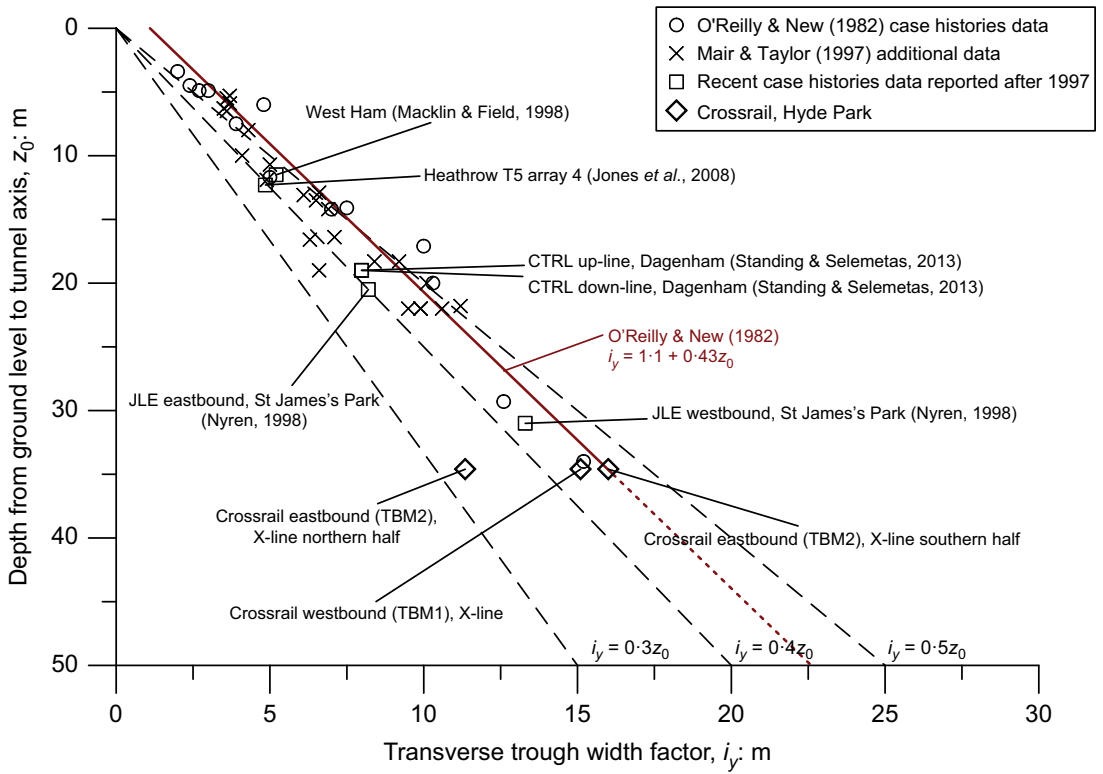

(a)

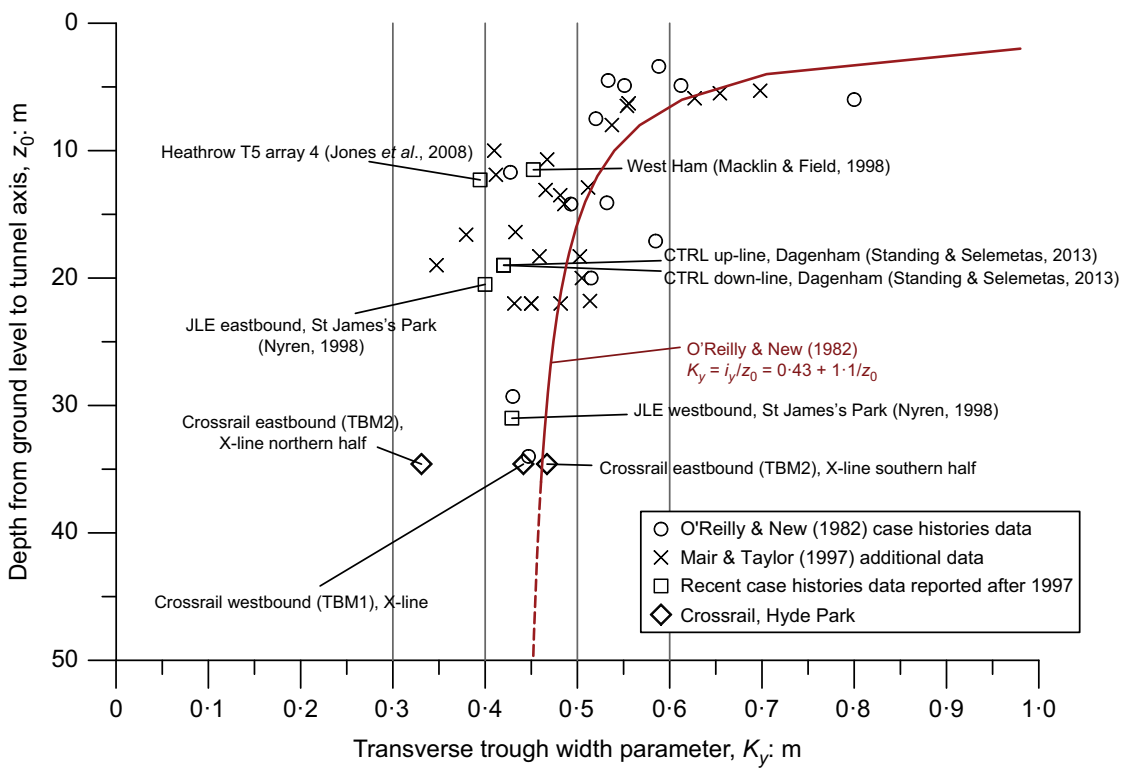

(b)

Fig. 16. Values of surface settlement (a) trough width factors and (b) trough width parameters plotted against depth from three instrumented sites in London

was about $200 \mathrm{kPa}$ or about $30 \%$ of the overburden pressure at the tunnel axis level.

\section{HORIZONTAL STRAINS AND DISPLACEMENTS}

Horizontal movements on $X$ - and Y-lines (periods 2 and 4)

The results from measurements using a micrometer stick on the $\mathrm{X}$ - and Y-lines are presented in this section. The micrometer stick measured changes in distance between pairs of SMPs, providing average horizontal strains over their $2.5 \mathrm{~m}$ spans (Standing et al., 2001). Transverse horizontal displacements $(v)$ are calculated by summing the change in spans between SMPs along a continuous monitoring line from an assumed stationary point (where $v=0$ ). For both lines this has been taken to be the point directly above the tunnel centre-line position since the outer points of the lines are considered to be within ground influenced by the tunnelling works. In the case of the X-line, its continuity was interrupted by the North Ride bridle path (between XSMP16 and
XSMP17). As the settlement trough and the transverse strain profile for the greenfield X-line are almost symmetrical, it is assumed that the transverse horizontal displacement at XSMP23 $(y=26.3 \mathrm{~m})$ is of the same magnitude as that at XSMP4 $(y=-26.4 \mathrm{~m})$ but with an opposite sign. In this way the displacements for XSMP17 to XSMP22 have been summed from the assumed displacement at XSMP23, as shown in Fig. 18(a). The maximum displacements either side are very similar, with $2.3 \mathrm{~mm}$ on the southern side (XSMP8, $y=-16 \cdot 4 \mathrm{~m}$ ) and $2 \cdot 2 \mathrm{~mm}$ on the northern side (XSMP20, $y=18.8 \mathrm{~m})$. These maximum displacements are the same as that along the southern side of the Y-line $(2 \cdot 2 \mathrm{~mm}$ at YSMP6: $y=-12.5 \mathrm{~m}$ ), indicating again that the southern half of the Y-line SMPs was outside any influence from the Central Line tunnels. Marginally larger maximum horizontal displacements of $3.0 \mathrm{~mm}$ developed on the northern side (YSMP18 to YSMP22: $17 \cdot 5 \mathrm{~m}<y<25 \cdot 0 \mathrm{~m})$, as shown in Fig. 18(b).

A succession of transverse horizontal strain $\left(\varepsilon_{y}\right)$ profiles measured on the $\mathrm{X}$ - and Y-line SMPs as TBM1 progressed is 


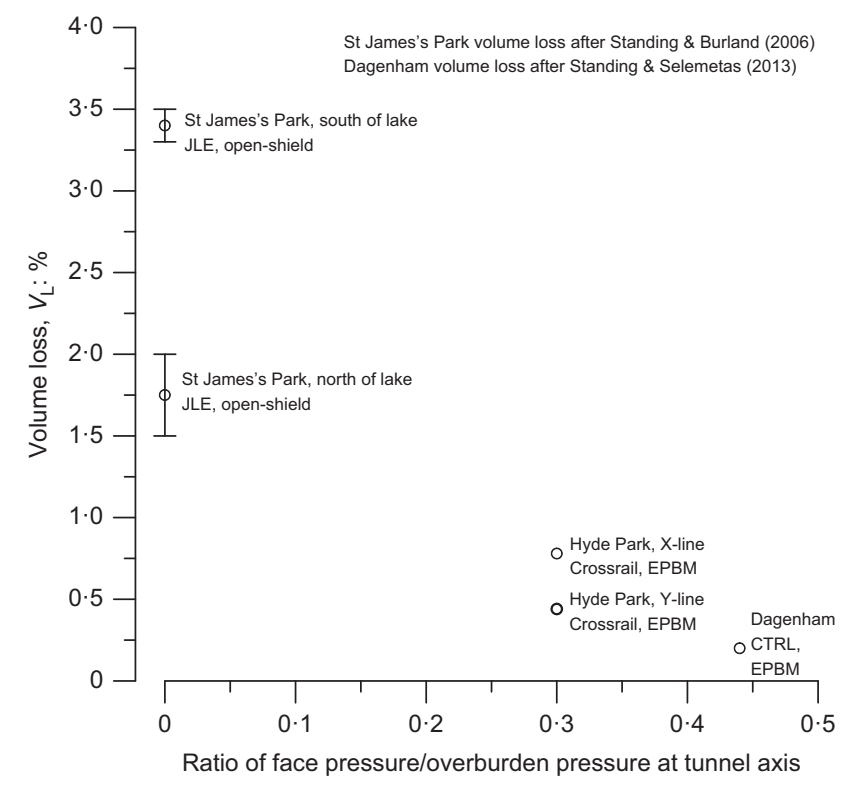

Fig. 17. Comparison of measured greenfield volume losses and face pressure ratios at three instrumented sites of tunnelling in London Clay

shown in Fig. 19. After TBM1 had passed, maximum compressive horizontal strains of 250 to $300 \mu \varepsilon$ had developed above the centre-line at both lines. Strains change from compressive to tensile at about $y= \pm 17 \cdot 5 \mathrm{~m}$ and $y=20 \mathrm{~m}$ for the $\mathrm{X}$ - and Y-lines, respectively, with maximum tensile strains of about $130 \mu \varepsilon$ and $100 \mu \varepsilon$. The strains at offset of $y>25 \mathrm{~m}$ on the X-line (XSMP27 to XSMP30) should be tending to zero, but the measurements are erratic and deemed not to be reliable (Fig. 19(a)).

Profiles of incremental transverse displacements along the $\mathrm{X}$ - and Y-line SMPs at the end of periods 2 and 4 are compared in Fig. 20(a) where it can be observed that, in general, the incremental displacements recorded at the end of period 4 are larger than those at the end of period 2. Despite the scattered nature of the incremental transverse strains shown in Fig. 20(b), the same trend is clearly evident, with greater strains developed during period 4 than period 2, for both tensile and compressive regions.

\section{Point-sink locations determined from measurements}

Having measurements of both vertical and horizontal surface displacements, the resultant vectors can be plotted to investigate the point-sink commonly assumed for determining horizontal surface displacements. The vectors for both X-and Y-lines for periods 2 and 4 (the latter based on incremental displacements) are presented in Fig. 21. Broken lines have been extrapolated from the vectors to assess whether there is a clearly defined point-sink and its location. It is immediately evident that there are well-defined point-sinks for both X-and Y-lines, but in quite different locations. Almost all the surface displacement vectors relating to the greenfield X-line are directed towards a clear point at the tunnel crown position for both periods (Figs 21(a) and 21(c)). The point-sink for the passage of TBM2 is located slightly southwards, towards the previously constructed westbound tunnel. The extrapolated lines for the three southernmost points shown are directed at much steeper angles, indicating greater components of vertical displacement than the other points. This can be attributed to the ground disturbance from the westbound tunnel construction and is corroborated by the wider southern-half settlement trough width shown in Fig. 13(a).
Clearly defined point-sinks are evident from most of the extrapolated vectors relating to the Y-line, but in this case they are located $2 \cdot 5 \mathrm{D}$ to $2 \cdot 0 \mathrm{D}$ above the tunnel centre-lines (Figs 21(b) and 21(d)). In comparing the response from the two lines the location of the resulting point-sinks can be directly related to: $(a)$ the vertical displacements, which were significantly larger on the X-line (compare Figs 11(a) and 13(a) with Figs 11(b) and 13(b)) causing a downwards shift of the point-sink; and $(b)$ the horizontal displacements, which were greater on the Y-line (compare lines in Fig. 20(a)) causing an upwards shift. In the case of the Y-line, for the passage of TBM1, there are markedly greater horizontal components of displacement at the northern end of the line, with them increasing towards the vicinity of the Central Line tunnels. This trend reverses for the passage of TBM2 with greater and increasing horizontal components to the southern end of the Y-line in the vicinity of where the westbound tunnel was constructed (although the southernmost points are beyond the centre-line of the tunnel).

For both X- and Y-lines the point-sink locations are above the centre-line of the tunnels, the position commonly adopted when predicting surface horizontal displacements. Using this assumption would lead to an under-estimation of horizontal displacements. Reasons for the difference in point-sink locations at the two lines cannot be given definitively, and are probably related to a combination of the two factors $(a)$ and $(b)$ given above. In this case study the magnitudes of horizontal displacement are very small $(<5 \mathrm{~mm})$ and relatively small differences in their values may have a significant effect on the point-sink location. However, there is in fact good confidence in the measurements, as discussed in the next section where comparisons are made with optical fibre measurements. The reason is more likely to be related to the measured settlements (and volume losses) being smaller than those at the X-line (because of the presence of the Central Line tunnels). If the vertical components of the resultant displacement vectors relating to the Y-line (shown in Figs 21(b) and 21(d)) were increased, the position of the point-sink would be deeper, but still above the axis of the tunnels. It is worth noting that Nyren (1998) also observed well-defined pointsink locations about $2 D$ above the axis of the tunnels in St James's Park for the JLE project, where the ground stratigraphy and conditions are similar to those in Hyde Park.

\section{Comparison of measurements with micrometer stick and optical fibre sensors}

A set of optical fibre sensor cables was installed in a shallow trench starting from and transverse to the westbound centre-line and running parallel to the X-line SMPs at an eastwards offset of $34 \mathrm{~m}$ : details are reported by Hauswirth et al. (2014). It was thus possible to measure, with a much greater spatial resolution $(1 \mathrm{~cm})$ and precision $(2 \mu \varepsilon)$, the surface horizontal ground strains and to generate a continuous transverse profile. As shown in Fig. 22(a), the results from the optical fibre sensors compare well with the micrometer stick measurements on the X-line SMPs for the passage of TBM1, with the point where strains change from compression to tension being the same, despite the lower accuracy of the micrometer stick measurements. Profiles of transverse horizontal displacements derived from the measured strains are shown in Fig. 22(b). For the optical fibre sensors, the displacements are derived by integrating the strain profile from the far end $(y=-60 \mathrm{~m})$ where zero displacement is assumed. Within the $25-\mathrm{m}$ distance from the tunnel centre-line, the horizontal displacements derived by both measurement methods agree very well, with very similar profile shapes and discrepancy in magnitude less than $0.5 \mathrm{~mm}$ (thus also giving confidence in the assumptions 


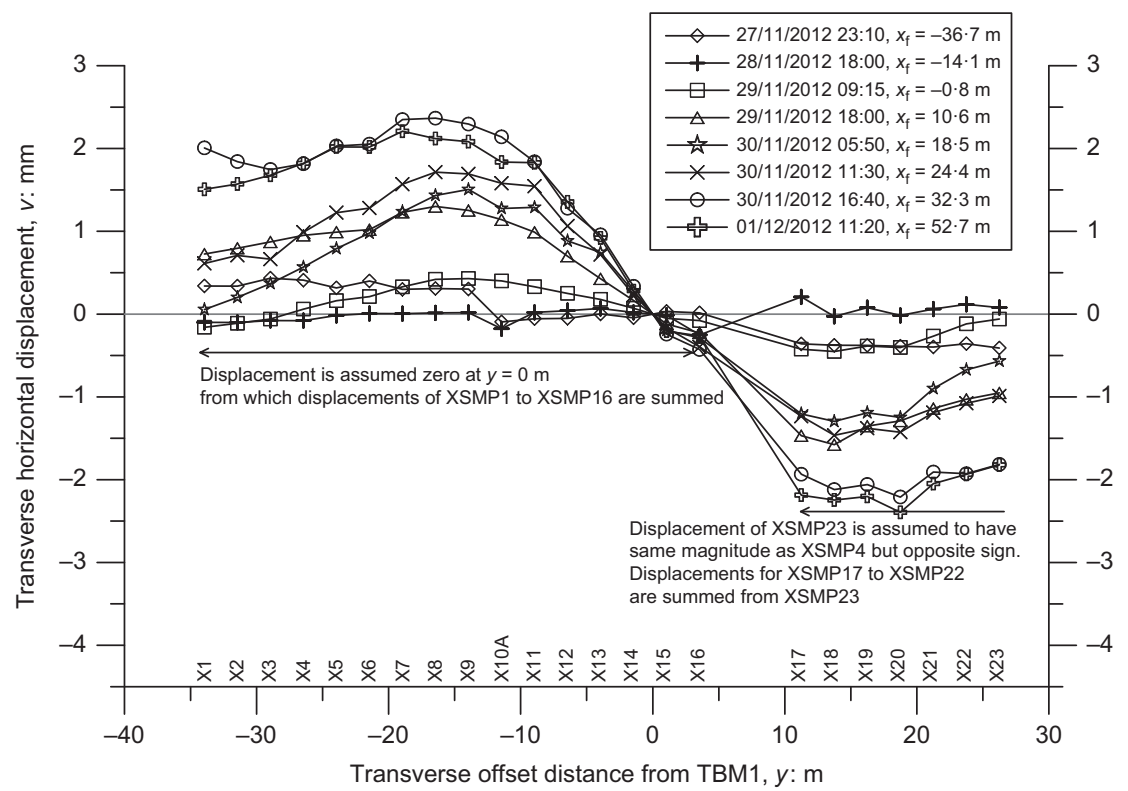

(a)

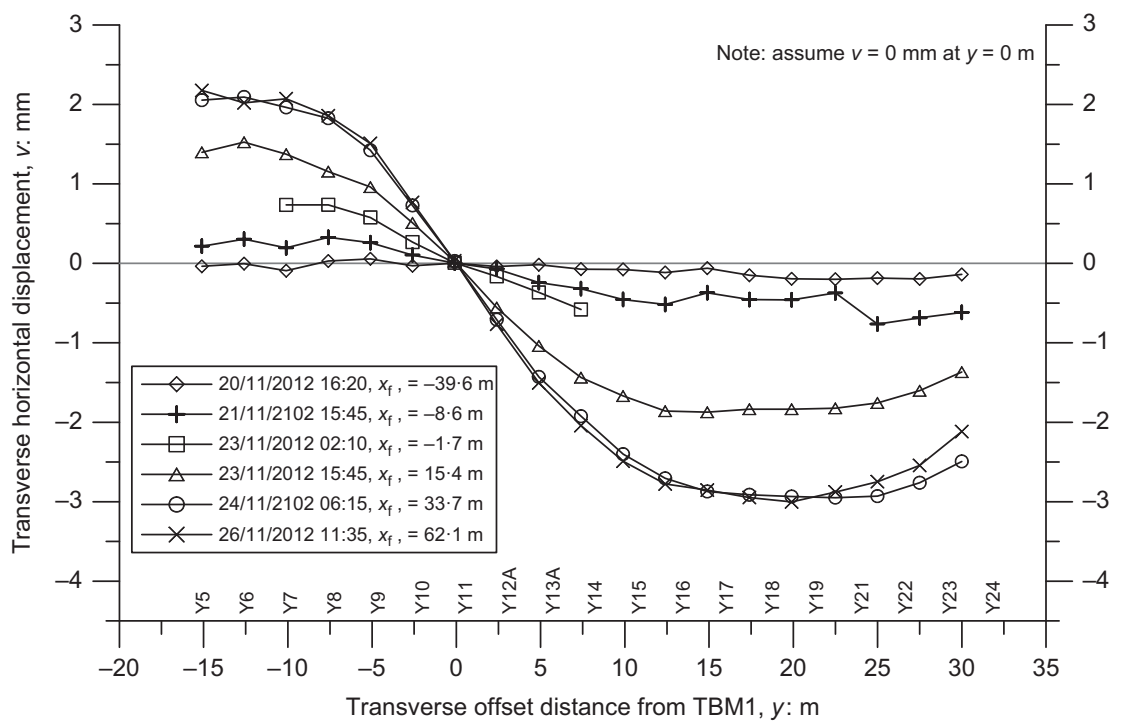

(b)

Fig. 18. Transverse profiles of transverse horizontal displacements from micrometer stick measurements during passage of TBM1 (period 2) at: (a) X-line SMPs; (b) Y-line SMPs

discussed earlier for determining the horizontal displacements along the X-line).

\section{CORRELATION BETWEEN SURFACE SETTLEMENT AND EPBM OPERATION VARIABLES}

It is widely accepted that the EPBM tunnelling technique is able to reduce tunnelling-induced ground movements by controlling operation variables such as the face pressure and tail grout volume and pressure. Construction of the two tunnels beneath Hyde Park provides an opportunity to investigate correlations between measured surface settlement volume losses and EPBM operation variables. In addition to the X- and Y-line SMPs monitored by the Imperial College team, ten lines of SMPs (in the form of survey nails on pavements) were installed along the tunnel alignments within Hyde Park and monitored by the Crossrail tunnel contractor BFK (BAM Nuttall, Ferrovial Agroman and Kier Construction). The locations of the monitoring lines along the tunnel alignments are shown with the associated volume losses determined in Fig. 23(a). The start and end chainages relate to the boundaries of Hyde Park, namely from Bayswater Road (ch. 2100 m) to Park Lane (ch. 3000 m). Variations in selected EPBM operation variables as each TBM passed beneath Hyde Park are shown in Figs 23(b)23(e). The data points shown in the figure are the rolling average values over ten lining rings, or $16 \mathrm{~m}$ lengths of tunnel drive. The volume losses derived from the surface settlement measurements range from $0.4 \%$ to $0.9 \%$ for the passage of TBM 1 and $0 \cdot 6 \%$ to $1 \cdot 6 \%$ for TBM2. In all cases the volume losses induced by TBM 2 are greater than those from TBM1, attributed to ground softening after the construction of the first tunnel.

Average face pressures for both TBM1 and TBM2 are about $200 \mathrm{kPa}$, with a variation of $\pm 50 \mathrm{kPa}$ over their $1 \mathrm{~km}$ passages beneath Hyde Park, as shown in Fig. 23(b), while average tail grout pressures are about $100 \mathrm{kPa}$ for TBM1 and $200 \mathrm{kPa}$ for TBM2 (Fig. 23(c)). These pressures are significantly smaller than the in situ overburden pressure $(\sim 650 \mathrm{kPa})$ and variations from the mean values are relatively minor. As a consequence of this, combined with the small magnitudes of volume losses determined, no clear 


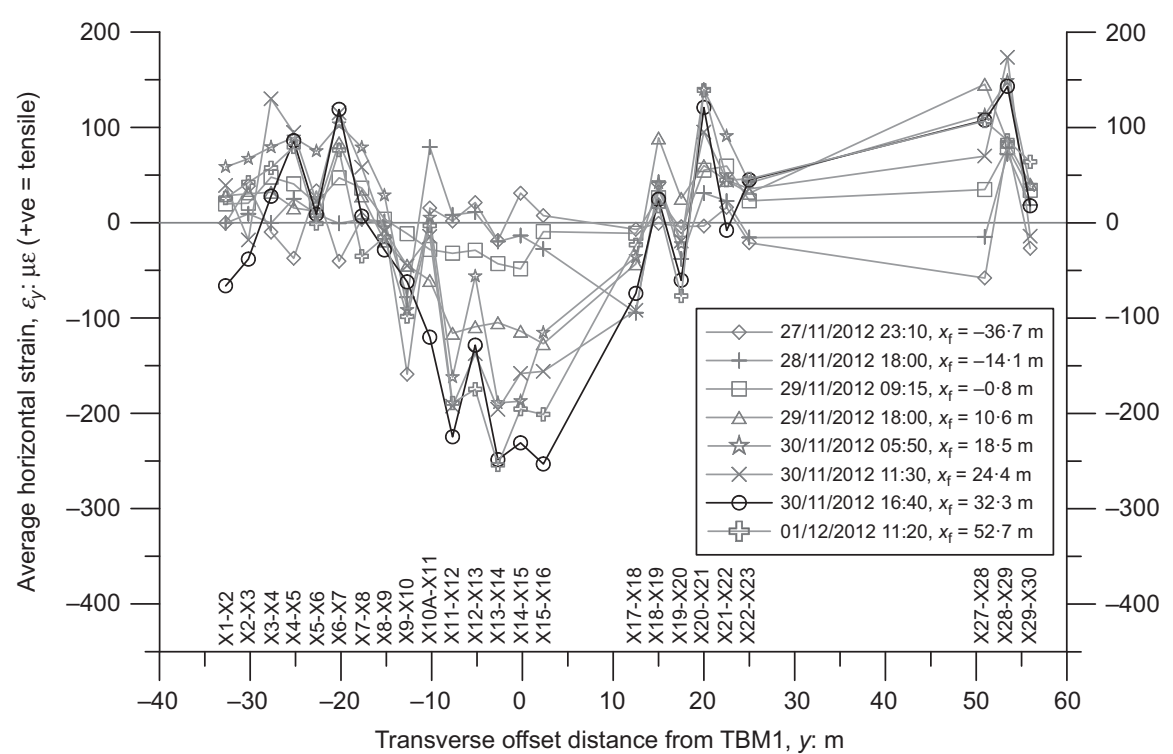

(a)

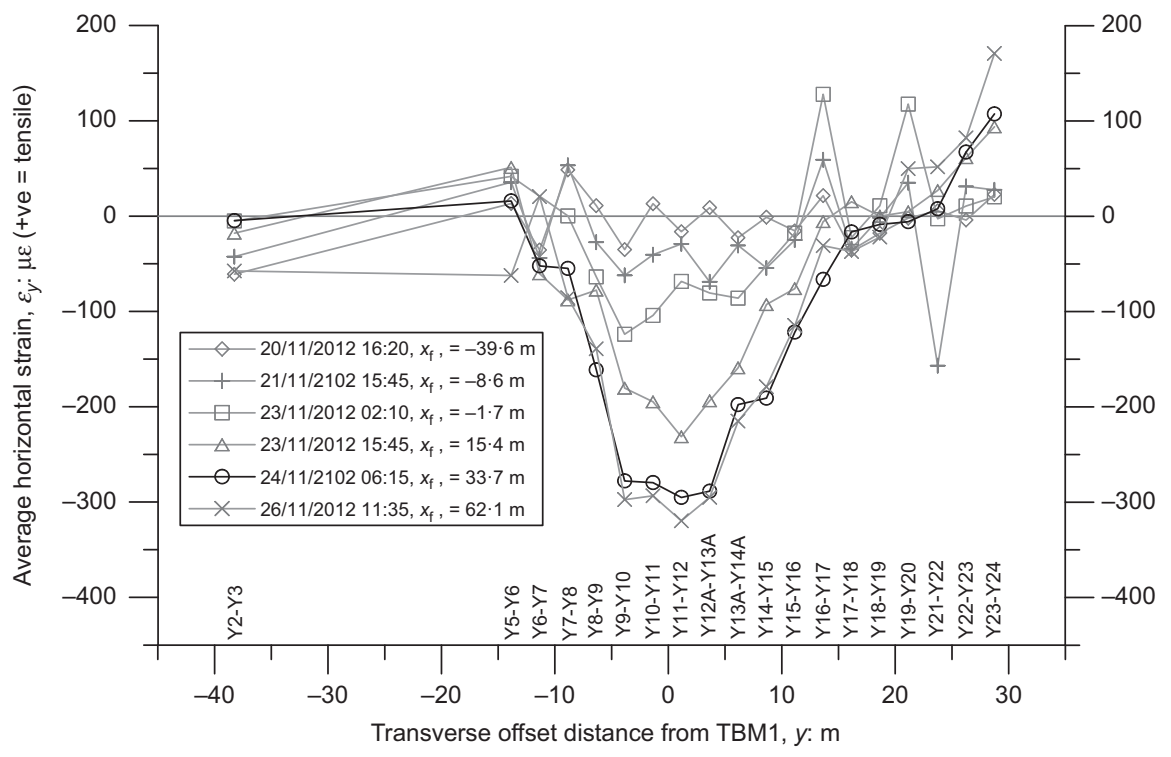

(b)

Fig. 19. Transverse profiles of average transverse horizontal strains from micrometer stick measurements during passage of TBM1 (period 2) at: (a) X-line SMPs; (b) Y-line SMPs

relationships are evident between volume loss and face pressure or tail grout pressure.

Variations in the average weight of excavated material, measured on the belt conveyor, are shown in Fig. 23(d) with values given in tonnes per shield advance of one lining ring width (i.e. $1.6 \mathrm{~m}$ ). Although the excavated soil was mixed with soil-conditioning fluid/foam, which would have changed its bulk density, the weights give a useful indication of the amount of soil excavated. The weight of excavated materials was roughly constant for both tunnel drives beneath Hyde Park, with weights varying within a narrow range of $125-135 \mathrm{t} / \mathrm{ring}$. Both values are larger than the theoretical weight (about 122.5 t/ring) of soil excavated by a $7 \cdot 10 \mathrm{~m}$ dia. cutter-head assuming a bulk unit weight of $19 \mathrm{kN} / \mathrm{m}^{3}$ for the London Clay spoil (shown as a broken line in the figure). Apart from the conditioning fluid/foam added, the weight in excess of the theoretical value is likely to reflect some degree of 'over-excavation' by the cutter-head as a consequence of inward ground movements towards the face and cutter-head periphery. Given that the dimensions of the TBM shields for both tunnels were identical (and hence so was the weight of theoretical excavated materials), it is evident from the figure that the amount of 'over-excavation' by the TBM 2 cutter-head was always larger than that of TBM1. This corroborates with the larger volume losses measured at the ground surface when TBM2 passed beneath Hyde Park (suggesting greater inward ground movements towards the tunnel).

Tail grout volumes injected per advance of one lining ring are shown in Fig. 23(e). This grout was injected to minimise further ground movement into the annular void between cut diameter of the tunnel excavation $(7 \cdot 1 \mathrm{~m})$ and the outer diameter of the newly erected tunnel lining ring $(6.8 \mathrm{~m})$. The theoretical volume of the annular void is $5 \cdot 24 \mathrm{~m}^{3} / \mathrm{ring}$ advance $(1.6 \mathrm{~m})$. It can be seen from the figure that the applied tail grout volumes were mostly lower than this value, probably because of inward ground movement, but with greater volumes injected from TBM2 because of the higher applied grout pressures (Fig. 23(c)). An assessment of the different components of volume loss (e.g. at the face, shield body, tail skin) is given in the companion paper where results from the subsurface instrumentation are discussed. 


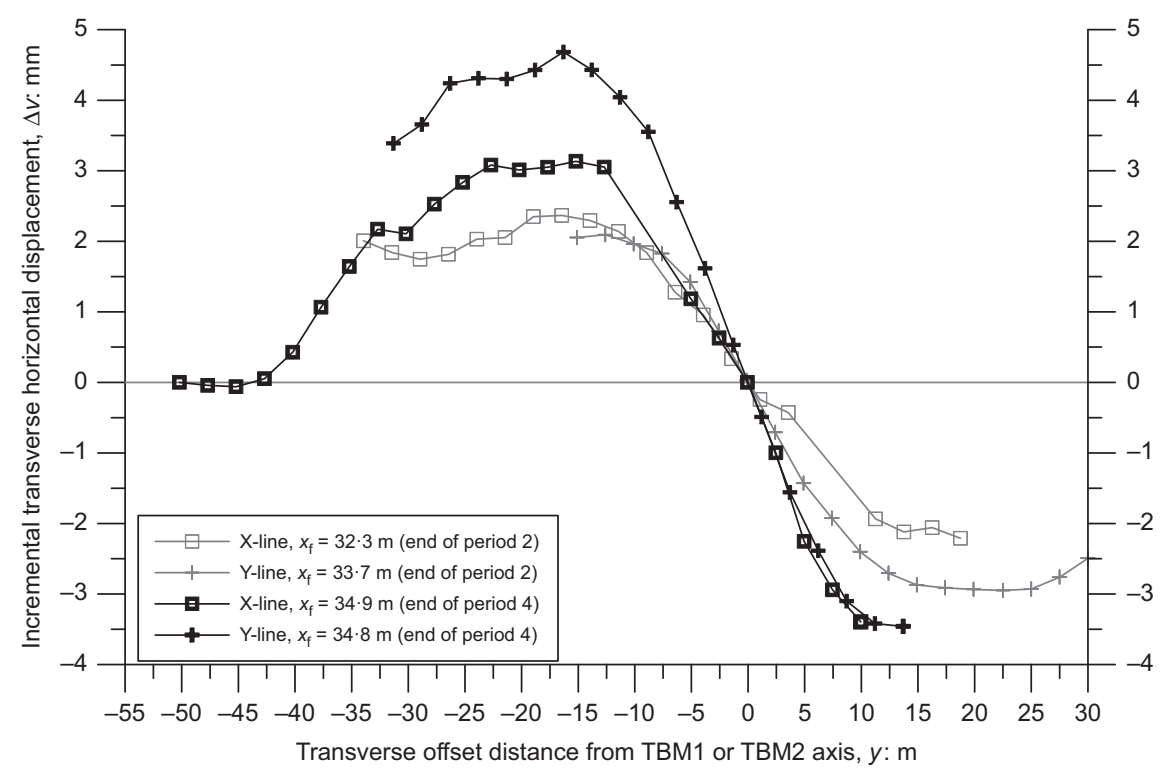

(a)

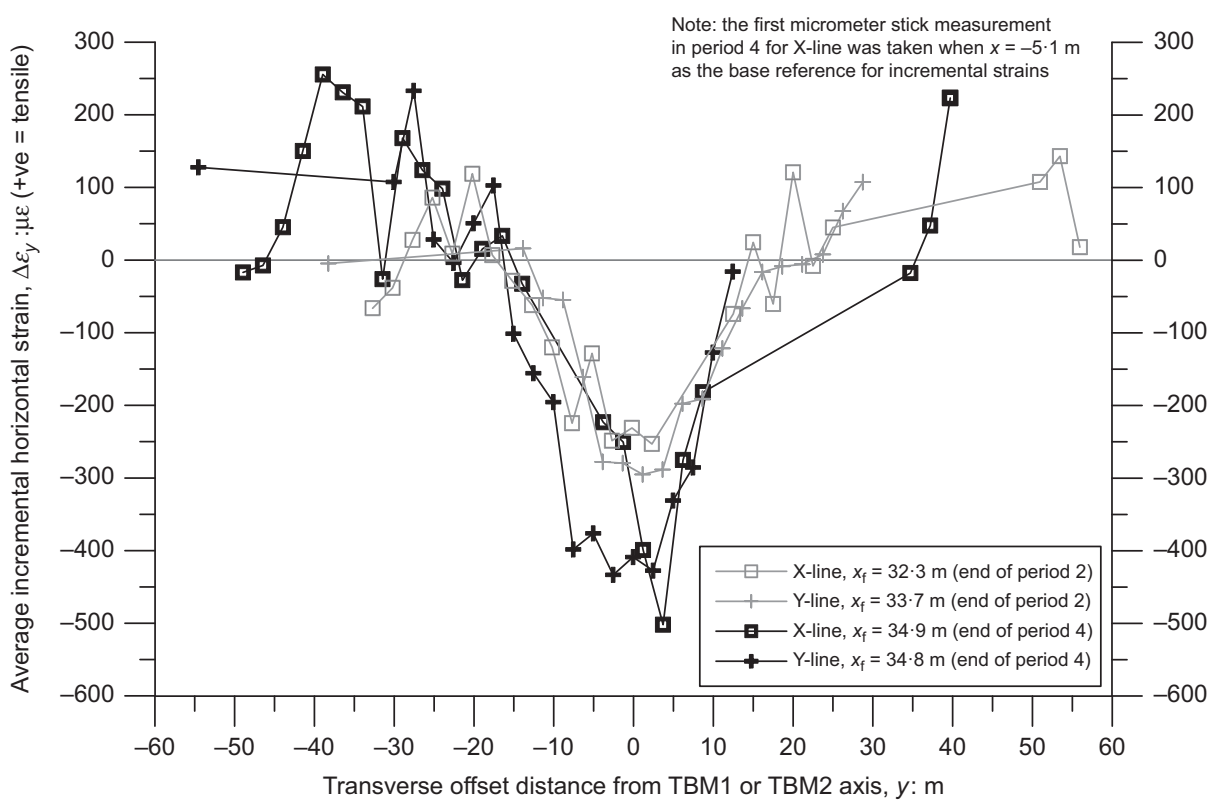

(b)

Fig. 20. Transverse profiles of (a) incremental transverse horizontal displacements and (b) average incremental transverse horizontal strains from micrometer stick measurements at the end of periods 2 and 4

\section{SUMMARY AND CONCLUSIONS}

Vertical and horizontal surface ground displacements measured (by precise levelling and micrometer stick) at an instrumented site in Hyde Park during the passage of two EPBMs at $34.5 \mathrm{mbgl}$ have been analysed and discussed. Three locations were monitored, two in the close proximity of the existing Central Line tunnels and the other in a greenfield condition. Measurements of horizontal displacements were confirmed by independent monitoring using optical fibre technology. Robotic total station measurements were also taken during the tunnel construction but had a reduced accuracy and so are not reported.

The observed settlement troughs can be reasonably modelled using the commonly adopted empirical Gaussian formulation. The transverse surface settlement trough width parameter $\left(K_{v}\right)$ determined for the greenfield ground is smaller than values previously reported for case histories for similar ground conditions but involving tunnels shallower than $30 \mathrm{mbgl}$. The Hyde Park data, together with the St James's Park (JLE) data, indicate that, for tunnels with axis levels deeper than $30 \mathrm{mbgl}$, $K_{y}$ falls within a range $0 \cdot 40<K_{y}<0 \cdot 45$.

Asymmetry of surface settlement troughs is evident in cases where the ground has been softened by previous tunnel construction, that is, close to the Central Line tunnels or after the first (westbound) Crossrail tunnel was constructed. Wider half-troughs develop on the side closer to pre-constructed tunnels. The effect was greater for the larger $7 \cdot 1 \mathrm{~m}$ dia. Crossrail tunnel (compared with the $3.8 \mathrm{~m}$ dia. Central Line tunnels) which, being more recently constructed, also meant that little subsequent consolidation of the ground (and hence partial re-strengthening of it) would have taken place.

In general, volume losses measured at the main lines of the SMPs in the instrumented site were low, being less than $0.8 \%$ and $1.4 \%$ for the first and second tunnel drives respectively, higher values being associated again with ground softening from the first tunnel construction. However, smaller volume losses were recorded in the vicinity of the existing Central Line tunnels, compared with the greenfield location, 

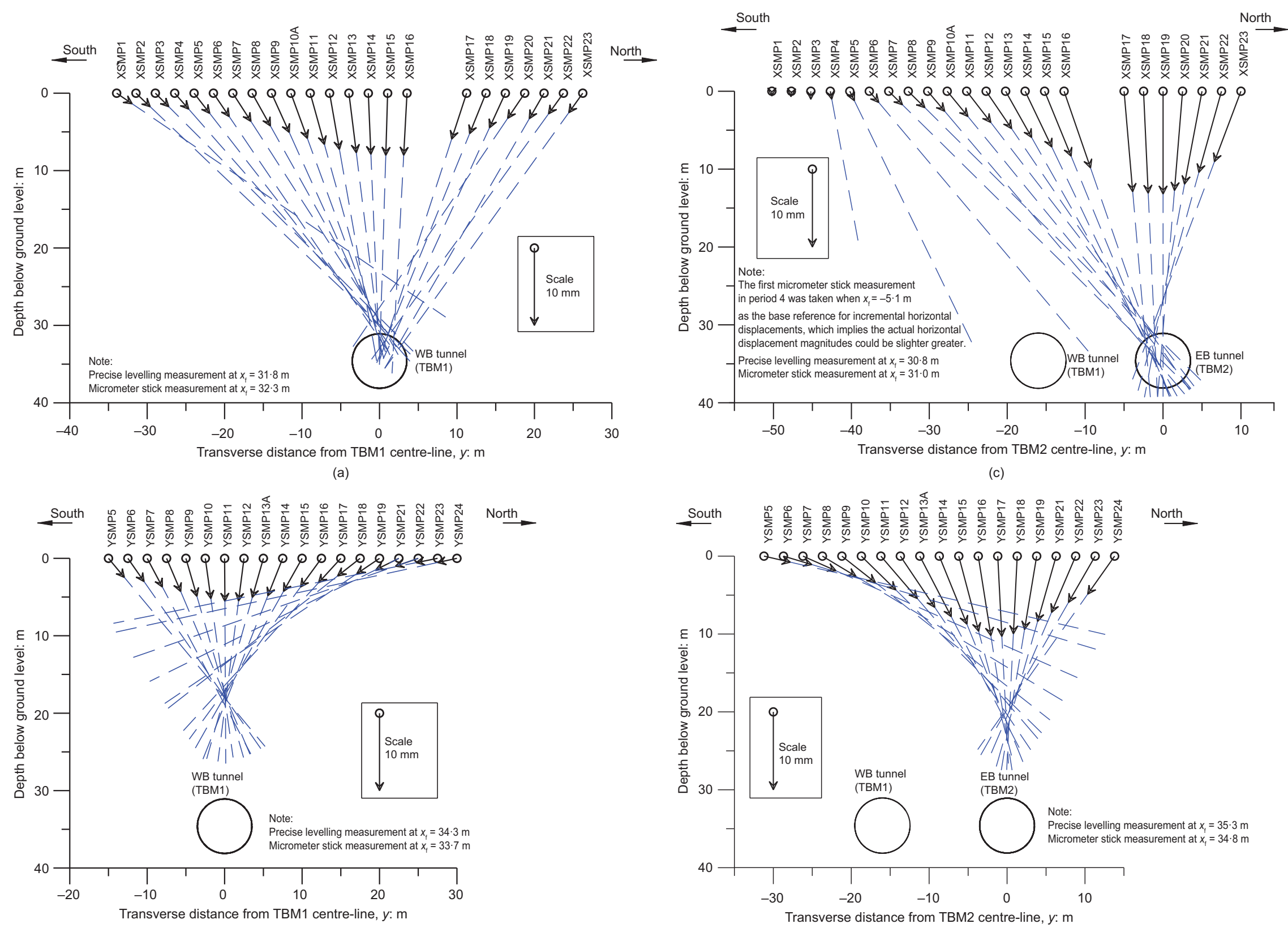


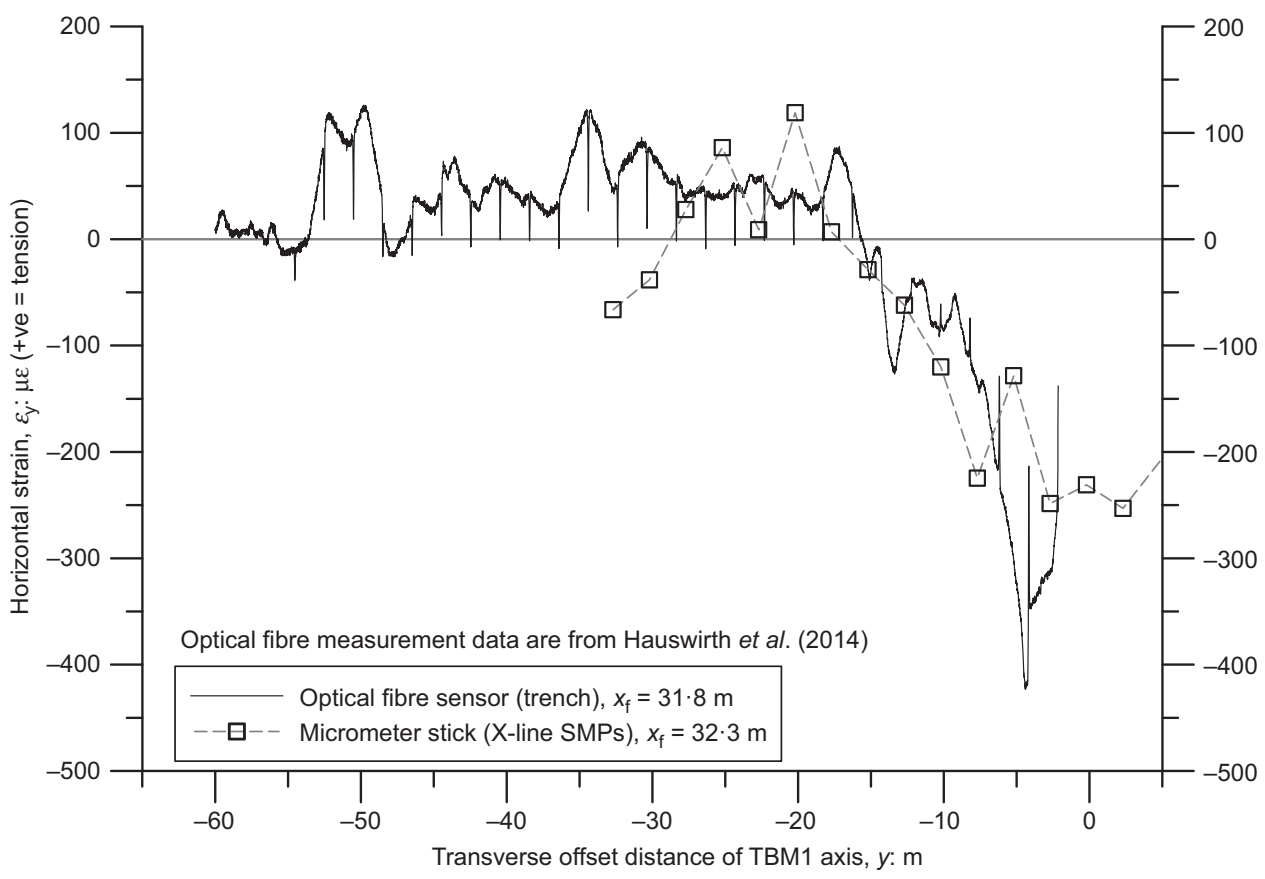

(a)

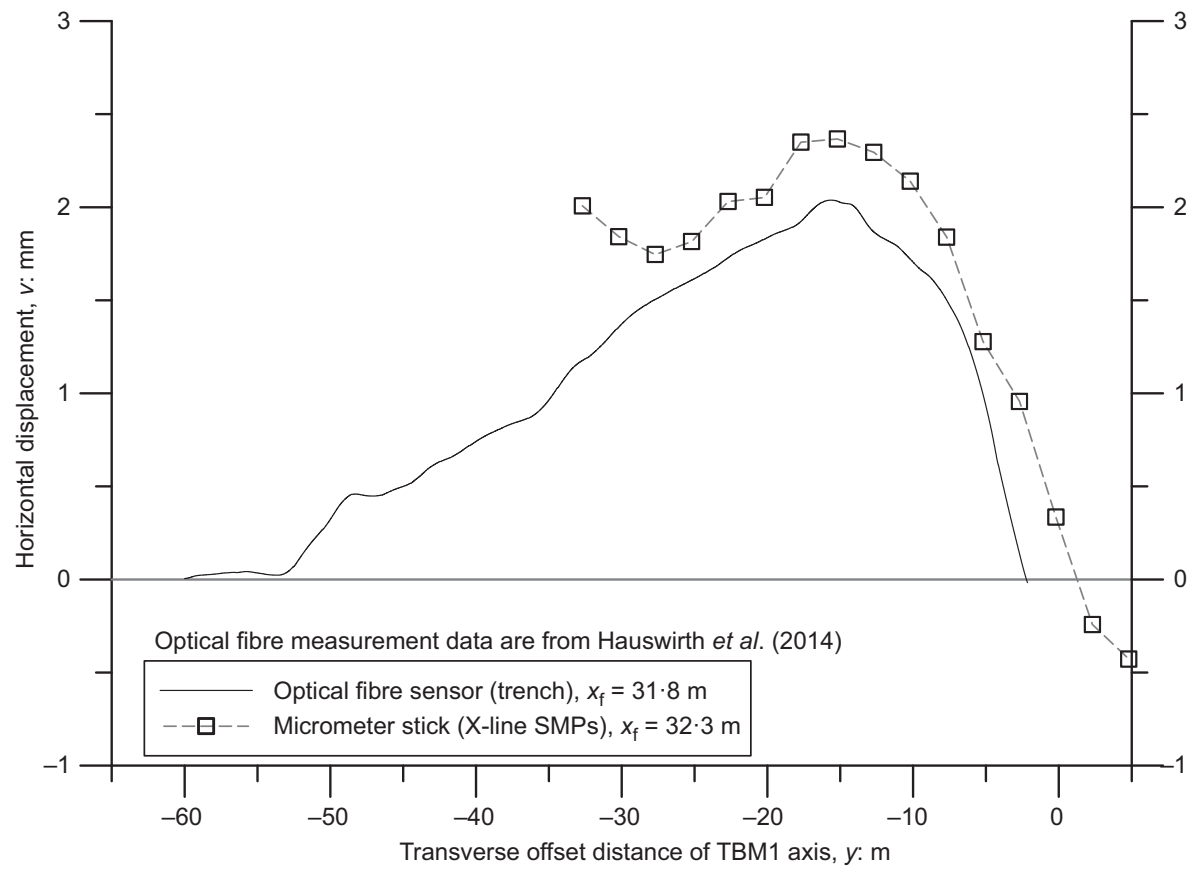

(b)

Fig. 22. Comparison of transverse profiles of (a) transverse horizontal strains and (b) transverse horizontal displacements measured by optical fibre sensors and micrometer stick after passage of TBM1 (end of period 2)

suggesting that their presence inhibited the development of ground movements.

Surface horizontal displacements, determined from micrometer stick measurements, were of the same form as those determined using a 'point-sink' assumption in conjunction with the Gaussian formulation. Resultant displacement vectors derived from the field measurements were directed to well-defined point-sinks located at distances of $0 \cdot 5 D$ to $2 \cdot 5 D$ above the tunnel axis level. The lower location (at roughly the tunnel crown) was observed for the greenfield condition - reasons for the differences are not clear.

EPBM operation variables were studied to investigate possible correlations with the surface ground response at the research site and also for another ten sections monitored by precise levelling within Hyde Park. Generally, variations in face or tail grout pressure were relatively small and this, in conjunction with the small magnitudes of volume loss determined, means correlations between them could not be readily identified.

Greater masses of excavated spoil were measured within the TBM2 shield compared with TBM1, suggesting a greater degree of 'over-excavation', again because of ground softening from the first tunnel construction (corroborated with the measured values of volume loss).

\section{ACKNOWLEDGEMENTS}

The authors wish to acknowledge the Engineering and Physical Sciences Research Council (EPSRC) (EP/G063486/1) and Crossrail who were the major sponsors 


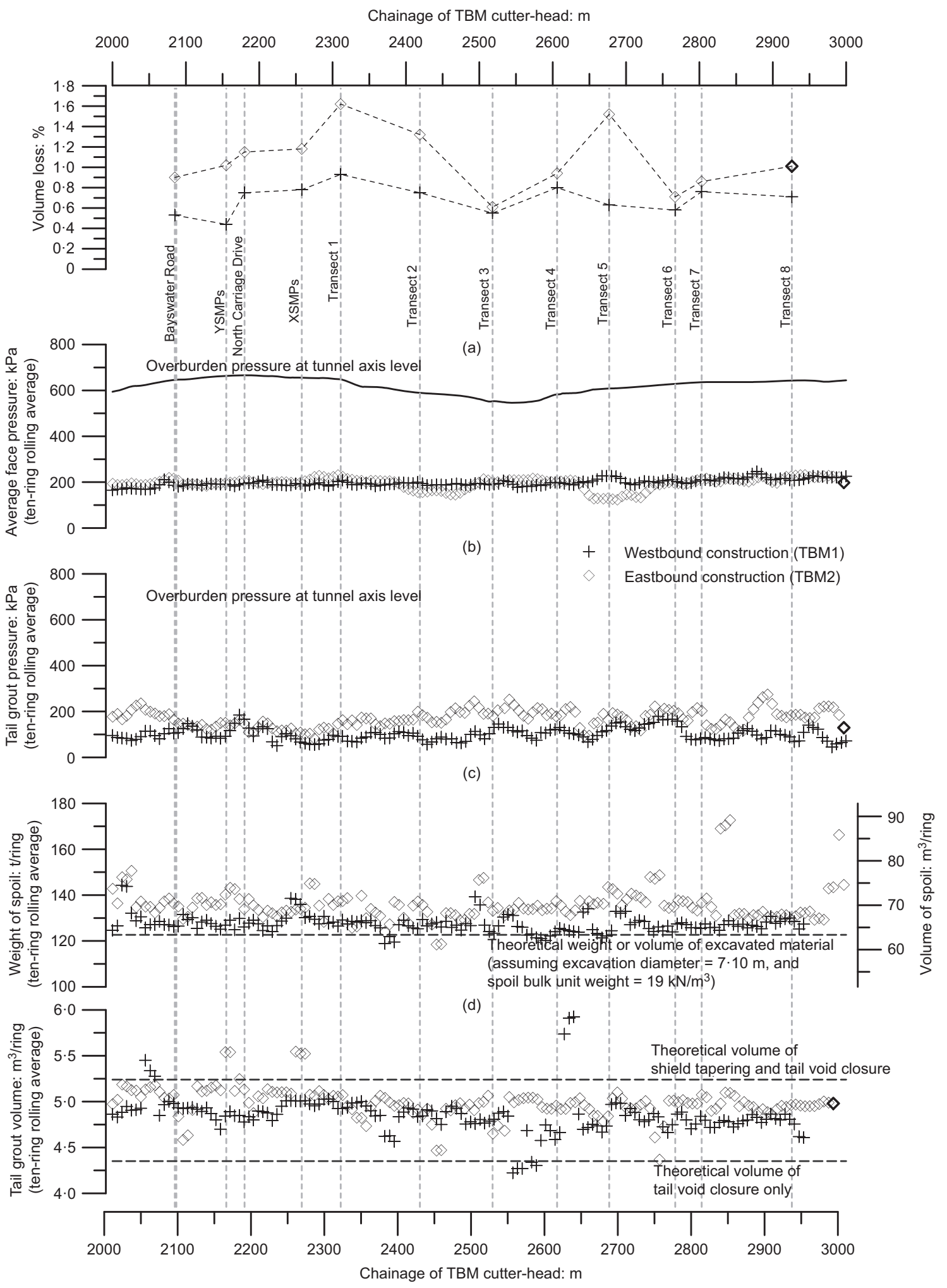

(e)

Fig. 23. Variation of measured surface volume losses and recorded EPBM operation variables with TBM chainage: (a) measured volume loss at ground surface; (b) measured face pressure behind cutter-head; (c) applied tail grout pressure; (d) weight of excavated materials on belt conveyor; (e) tail grout volume injected

for this field component of the research project. Many thanks are due to the Imperial College research team, especially the Imperial College technician $\mathrm{Mr}$ Alan Bolsher, and those others who helped take the field measurements during the 24-h surveying periods. A thoughtful review of the instrumentation plan by $\mathrm{Mr}$ John Dunnicliff is also greatly appreciated. The support provided by the Royal
Parks, London Underground Limited and Westminster Council during the installation work is gratefully acknowledged. The authors are also grateful to the main joint venture contractors BFK, in particular Mr Ivor Thomas, for providing data and information relating to the TBMs, their operational variables and the settlement monitoring data across Hyde Park. 


\section{REFERENCES}

Addenbrooke, T. I., Potts, D. M. \& Puzrin, A. M. (1997). The influence of pre-failure soil stiffness on the numerical analysis of tunnel construction. Géotechnique 47, No. 3, 693-712, http://dx.doi.org/10.1680/geot.1997.47.3.693.

Attewell, P. B. (1978). Ground movements caused by tunnelling in soil. Proceedings of conference on large ground movements and structures, Cardiff, UK (ed. J. D. Geddes), pp. 812-948. London, UK: Pentech Press.

Avgerinos, V. (2014). Numerical investigation of tunnelling beneath existing tunnels. $\mathrm{PhD}$ thesis, Imperial College London, London, UK.

BRE (Building Research Establishment) (1993). Monitoring building and ground movement by precise levelling, Building Research Establishment Digest 386. Garston, UK: IHS BRE Press.

Cooper, M. L., Chapman, D. N., Rogers, C. D. F. \& Chan, A. H. C. (2002). Movements in the Piccadilly Line tunnels due to the Heathrow Express construction. Géotechnique 52, No. 4, 243-257, http://dx.doi.org/10.1680/geot.2002.52.4. 243.

Fearnhead, N., Maniscalco, K., Standing, J. R. \& Wan, M. S. P. (2014). Deep excavations: monitoring mechanisms of ground displacement. Proc. Instn Civ. Engrs - Geotech. Engng 167, No. 2, 117-129.

Grammatikopoulou, A., Zdravkovic, L. \& Potts, D. M. (2008). The influence of previous stress history and stress path direction on the surface settlement trough induced by tunnelling. Géotechnique 58, No. 4, 269-281, http://dx.doi.org/10.1680/ geot.2008.58.4.269.

Hauswirth, D., Puzrin, A. M., Carrera, A., Standing, J. R. \& Wan, M. S. P. (2014). Use of fibre optic sensors for simple assessment of ground surface displacements during tunnelling. Géotechnique 64, No. 10, 837-842, http://dx.doi.org/10.1680/ geot.14.T.009.

Jones, B. D., Thomas, A. H., Hsu, Y. S. \& Hilar, M. (2008). Evaluation of innovative sprayed-concrete-lined tunnelling. Proc. Instn Civ. Engrs - Geotech. Engng 161, No. 3, $137-149$.

King, C. (1981). The stratigraphy of the London Basin and associated deposits, Tertiary Research Special Paper, vol. 6. Rotterdam, the Netherlands: Backhuys.

Macklin, S. R. \& Field, G. R. (1998). The response of London Clay to full-face TBM tunnelling at West Ham, London. Proceedings of international conference on urban ground engineering, Hong Kong.

Mair, R. J. \& Taylor, R. N. (1997). Bored tunnelling in the urban environment: State-of-the-art report and theme lecture. Proceedings of 14th International conference on soil mechanics and foundation engineering, Hamburg, Germany, vol. 4, pp. 2353-2385.
Nyren, R. (1998). Field measurements above twin tunnels in London Clay. PhD thesis, Imperial College, University of London, London, UK.

O'Reilly, M. P. \& New, B. M. (1982). Settlements above tunnels in the United Kingdom - their magnitude and prediction. In Tunnelling '82 (ed. M. J. Jones), pp. 173-181. London, UK: Institution of Mining and Metallurgy.

Selemetas, D. (2005). The response of full-scale piles and piled structures to tunnelling. $\mathrm{PhD}$ thesis, University of Cambridge, Cambridge, UK.

Standing, J. R. \& Burland, J. B. (2006). Unexpected tunnelling volume losses in the Westminster area, London. Géotechnique 56, No. 1, 11-26, http://dx.doi.org/10.1680/geot.2006.56.1.11.

Standing, J. R. \& Selemetas, D. (2013). Greenfield ground response to EPBM tunnelling in London Clay. Géotechnique 63, No. 12, 989-1007, http://dx.doi.org/10.1680/geot.12.P.154.

Standing, J. R., Withers, A. D. \& Nyren, R. J. (2001). Measuring techniques and their accuracy. In Building response to tunnelling, case studies from construction of the Jubilee Line Extension, London, vol. 1: projects and methods (eds J. B. Burland, J. R. Standing and F. M. Jardine), CIRIA SP200, Ch. 18, pp. 273-299. London, UK: CIRIA and Thomas Telford.

Standing, J. R., Potts, D. M., Vollum, R., Burland, J. B., Tsiampousi, A., Afshan, S., Yu, J. B. Y., Wan, M. S. P. \& Avgerinos, V. (2015). Investigating the effect of tunnelling on existing tunnels. Proceedings of conference on underground design and construction, Hong Kong, pp. 301-312. Hong Kong: IOM3, Hong Kong Branch.

Wan, M. S. P. (2014). Field monitoring of ground response to EPBM tunnelling close to existing tunnels in London Clay. PhD thesis, Imperial College London, London, UK.

Wan, M. S. P. \& Standing, J. R. (2014a). Lessons learnt from installation of field instrumentation. Proc. Instn Civ. Engrs Geotech. Engng 167, No. 5, 491-506.

Wan, M. S. P. \& Standing, J. R. (2014b). Field measurement by fully grouted vibrating wire piezometers. Proc. Instn Civ. Engrs Geotech. Engng 167, No. 6, 547-564.

Withers, A. D. (2001). Surface displacements at three surface reference sites above twin tunnels through the Lambeth Group. In Building response to tunnelling, case studies from construction of the Jubilee Line Extension, London, vol. 2: case studies (eds J. B. Burland, J. R. Standing and F. M. Jardine), CIRIA SP200, Ch. 37, pp. 735-752. London, UK: CIRIA and Thomas Telford.

Wongsaroj, J., Borghi, F. X., Soga, K., Mair, R. J., Sugiyama, T., Hagiwara, T. \& Bowers, K. J. (2006). Effect of TBM driving parameters on ground surface movements. In Proceedings of international symposium of geotechnical aspects of underground construction in soft ground (eds K. J. Bakker, A. Bezuijen, W. Broere and E. A. Kwast), pp. 335-341. London, UK: Taylor \& Francis Group. 